\title{
IDENTIFICATION OF SYNTHETIC DIAMOND GROWN USING CHEMICAL VAPOR DEPOSITION (CVD)
}

\author{
Philip M. Martineau, Simon C. Lawson, Andy J. Taylor, \\ Samantha J. Quinn, David J. F. Evans, and Michael J. Crowder
}

\begin{abstract}
Studies carried out at the DTC Research Centre have shown that single-crystal CVD synthetic diamond is clearly distinguishable from natural diamond. This article presents information about the CVD process, the history of its development, the different kinds of CVD synthetic diamond material that can be produced, and properties that differentiate them from natural diamond. The authors studied more than a thousand CVD synthetic diamond samples that were grown for research purposes using a range of different process conditions. Absorption, photoluminescence, and cathodoluminescence spectra of these CVD synthetic diamond samples showed a range of different impurity-related features not seen in natural diamond. Photoluminescence imaging is also useful in identifying CVD synthetic diamond, and X-ray topography may give supportive evidence. The effectiveness of the Diamond Trading Company Diamond Verification Instruments for identifying CVD synthetic diamond is also described.
\end{abstract}

S ynthetic diamond has occasionally been encountered by the gem trade, but until recently attention has focused almost exclusively on the kind produced by exposing carbon-containing solids to high pressures and temperatures (HPHTgrown synthetic diamond; see, e.g., Shigley et al., 1986, 1987). For many years, however, scientists have known that it is also possible to synthesize diamond at low pressures from carbon-containing gases, using chemical vapor deposition (CVD) techniques. Although the gem trade has been relatively unaware of CVD, over the last two decades this method of diamond synthesis has been the subject of intense worldwide research because of the many potential technological applications of CVD synthetic diamond material.

Apollo Diamond Inc. of Boston, Massachusetts, has spent many years developing CVD synthetic diamond material for use in technological applications and jewelry. In August 2003, this company announced plans to begin selling limited quantities of faceted material starting in the fourth quarter of 2003 (Pridy, 2003).

Butler et al. (2002) presented analytical results for one faceted sample of single-crystal CVD synthetic diamond produced by Apollo Diamond. Preliminary notes on examination of several Apollo samples appeared in the Gem News International section of the Fall 2003 issue of this journal. Then, in the Winter 2003 issue, Wang et al. gave a thorough description of the results of their study of 13 samples provided by Apollo Diamond, offering useful indicators to aid identification of CVD synthetic diamond of the kind proposed for commercial jewelry production.

Since the late-1980s, the Diamond Trading Company, a De Beers Group company, has carried out proactive research to investigate the implications

See end of article for About the Authors and Acknowledgments. Gems \& Gemology, Vol. 40, No. 1, pp. 2-25.

(C) 2004 Gemological Institute of America 


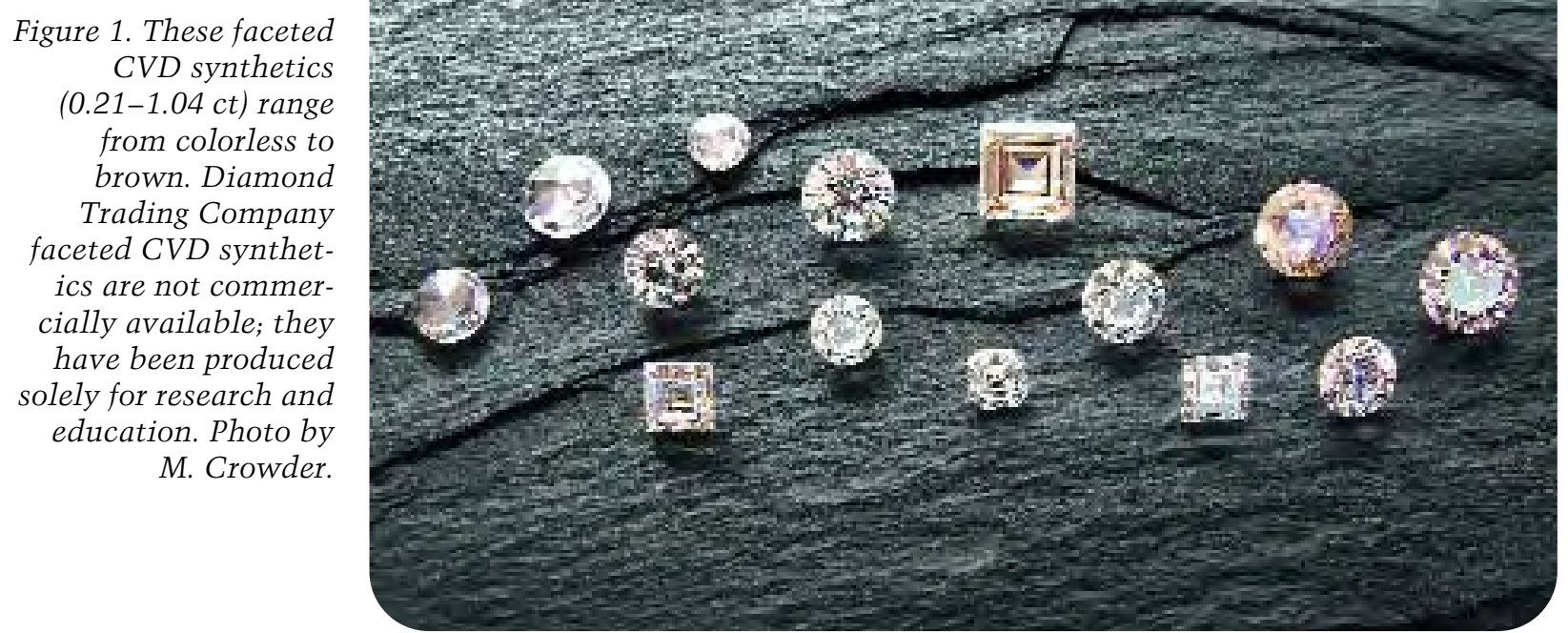

of CVD diamond synthesis for the gem trade. The purpose of this research has been to develop understanding of the properties of CVD synthetic diamond, so that an effective and practical methodology for distinguishing it from natural diamond could be developed ahead of the marketing of CVD synthetics for jewelry by companies such as Apollo Diamond. As part of these experiments, faceted stones have been produced from some of the synthetic diamond samples (see, e.g., figure 1). As with HPHT-grown synthetic diamond, scientists at the DTC Research Centre in Maidenhead (UK) have developed an advanced understanding of the growth and properties of CVD synthetic diamond. Information from this research program can now be disseminated to help the gem trade in the identification of material of the kind being commercially produced.

The aim of the present article is to provide gemologists with a broader understanding of the CVD process, the history of its development, the different kinds of CVD synthetic diamond material that can be produced, and the properties that differentiate them from natural diamond. Information is presented that will further help gemologists identify the kind of CVD synthetic diamond that is being offered commercially, including the use of Diamond Verification Instruments that have been developed by the Diamond Trading Company.

\section{CVD DIAMOND SYNTHESIS}

In contrast to the more widely known HPHT-grown synthetic diamond, CVD synthetic diamond is produced at low pressures, typically in the region of one-tenth of atmospheric pressure, from carbon-con- taining gases such as methane (see, e.g., Bachmann, 1998; Goodwin and Butler, 1998). This method of synthesis involves breaking up gas molecules into reactive species from which diamond can be grown. This can be done in a number of ways, resulting in a family of related growth techniques.

In perhaps the most common CVD method, the gas molecules (usually methane and hydrogen) are broken apart in a high-temperature plasma generated using microwaves in a reactor of the kind shown schematically in figure 2. Grotjohn and Asmussen (2002) described this method-microwave plasmaassisted CVD—in a recent review. Yehoda (2002), Wolden (2002), and Heberlein and Ohtake (2002) have reviewed other techniques that involve the use of a hot filament, flame, or plasma jet.

CVD synthetic diamond is generally grown on a substrate held at a temperature in the region of $800-1000^{\circ} \mathrm{C}$. For many industrial applications, silicon or metal substrates are used and the material grown is polycrystalline, because multiple crystals nucleate with different crystallographic orientations in different positions on the substrate (see, e.g., Wild et al., 1993). It is extremely difficult to polish such material into anything resembling a traditional gemstone. A single-crystal diamond substrate can, however, be used as a template for further singlecrystal growth in which synthetic diamond grows with the same crystallographic orientation everywhere on the substrate. This is termed homoepitaxy. If grown to a great enough thickness, CVD synthetic diamond produced in this way can be polished into faceted stones for jewelry applications.

HPHT diamond synthesis is typically carried out at temperatures and pressures (in the region of 


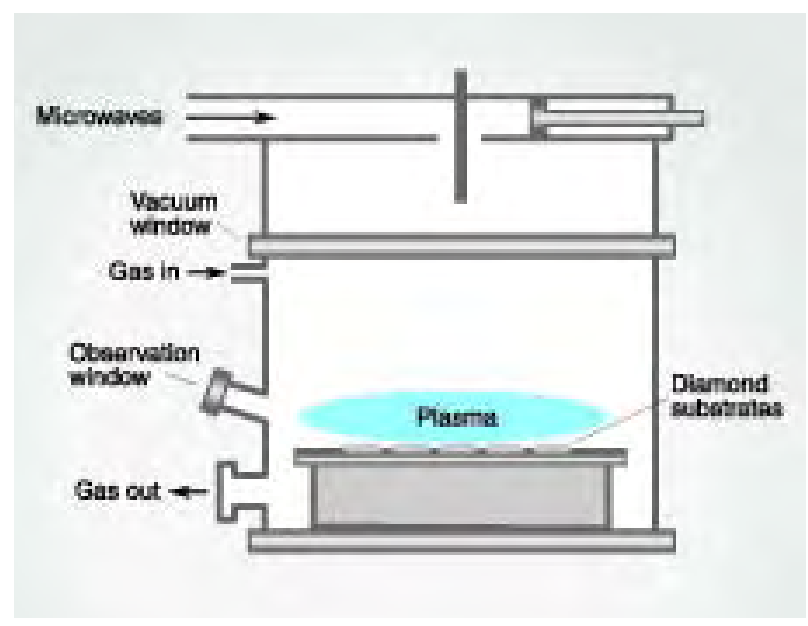

Figure 2. This schematic diagram depicts a microwave CVD reactor of the kind used to grow CVD synthetic diamond. The molecules of the starting gases, usually methane and hydrogen, are dissociated in a plasma that is generated using microwaves. The chemical species created react at the surface of seed crystals (substrates) mounted at the base of the reactor to form CVD diamond material. The diameter of the usable growth area may range between approximately 2 and $20 \mathrm{~cm}$.

$1400^{\circ} \mathrm{C}$ and $55 \mathrm{kbar}$ ) at which diamond is the most stable form of carbon. Under the low-pressure conditions used in CVD synthesis, diamond is metastable. This means that it does not spontaneously convert to graphite, although steps must be taken to prevent graphite from forming. Standard CVD processes use a hydrogen-rich gas mixture, and the atomic hydrogen generated in the CVD process has an important role in suppressing the formation of graphite (see, e.g., Goodwin and Butler, 1998).

\section{HISTORICAL BACKGROUND}

In 1952, William Eversole, of U.S.-based Union Carbide Corp., demonstrated homoepitaxial growth of diamond at low pressures from a carbon-containing gas (Kiffler, 1956; Eversole, 1962a,b; Angus, 2002). This predates the synthesis of diamond at high pressures and high temperatures (in February 1953) at ASEA in Sweden (see, e.g., Davies, 1984) and (in December 1954) at General Electric Co. in the U.S. (Bundy et al., 1955). Eversole is therefore believed to have been the first person to synthesize diamond by any method.

The CVD growth rates, however, were initially extremely low, and there was considerable skepticism that they could ever be increased enough to make the process commercially viable. Russian research into low-pressure diamond synthesis, initiated in 1956, led to higher growth rates and demonstrated that CVD synthetic diamond could be nucleated on materials other than diamond (Angus, 2002).

In the early 1980s, a major breakthrough was made in Japan. Matsumoto et al. (1982a,b), researchers at the National Institute for Research in Inorganic Materials (NIRIM), reported CVD synthetic diamond growth rates of over $1 \mu \mathrm{m} /$ hour $(1 \mu \mathrm{m}=$ $0.001 \mu \mathrm{m})$. This development led to worldwide interest in CVD synthesis, stimulated by the various potential industrial applications of CVD synthetic diamond that many scientists believed to be within reach, exploiting diamond's superlative optical, mechanical, thermal, and electronic properties.

In the late 1980s, Element Six (then the De Beers Industrial Diamond Division) started research into CVD diamond synthesis and rapidly became a leader in the field (Valentine et al., 1994; Wort et al., 1994; Sussmann et al., 1994; Coe and Sussmann, 2000), with a substantial portfolio of polycrystalline CVD synthetic diamond industrial products (see, e.g., figure 3). Since the late 1980s, the Diamond Trading Company has made good use of these capabilities to explore the significance of CVD synthetic diamond for the gem trade. Today, through contract research, it continues to use the growth expertise of Element Six in its Consumer Confidence Technical Research Program.

Although the increased growth rates demonstrated at NIRIM represented an important breakthrough for the production of the relatively thin diamond layers necessary for some industrial applications, production of faceted CVD synthetics for jewelry required growth of thick layers of single-crystal diamond material. A 0.5 ct round brilliant has a depth of over $3 \mathrm{~mm}$ and, at $1 \mu \mathrm{m} /$ hour, a CVD layer of this thickness would take almost 18 weeks to grow. Production of thick singlecrystal CVD synthetic diamond was therefore still hindered by the low growth rates.

Importantly, there was also a tendency for anything but very thin layers to crack during growth, and some researchers found that the overgrowth often contained rogue crystallites (see, e.g., Tsuno et al., 1994). Some people believed these problems and the low growth rates made CVD synthesis an impractical route for production of single-crystal material thick enough for jewelry applications. Initially, discussion of CVD synthetic diamond in the gem trade 
was limited to possible coating of polished natural stones to affect their color. For example, boron-doped CVD synthetic diamond coatings can add a blue color. Surface finish is, however, badly affected and such coated diamond is easily detected (Fritsch et al., 1989). In the 1990s, E. Fritsch reported on the use of polycrystalline diamond to produce novel kinds of jewelry (Johnson and Koivula, 1997), distinct from single-crystal diamond jewelry.

Most research into single-crystal CVD synthetic diamond has involved very thin layers, usually less than $0.1 \mathrm{~mm}$. Beginning in the early 1990s, however, a number of research groups published studies of the growth of somewhat thicker CVD synthetic diamond. For example, researchers at Nijmegen University, the Netherlands, reported flame and hot filament growth of layers up to $0.5 \mathrm{~mm}$ thick (Janssen et al., 1990, 1991; Schermer et al., 1994, 1996). In the U.S., Crystallume (Landstrass et al., 1993; Plano et al., 1994) used microwave CVD to produce layers of similar thickness, and Badzian and Badzian (1993) described a layer of single-crystal synthetic diamond that was $1.2 \mathrm{~mm}$ thick.

More recently, Linares and Doering (1999) and Yan et al. (2002) described the properties of layers of single-crystal CVD synthetic diamond, and-as

Figure 3. The polycrystalline CVD synthetic diamond optical window shown here was manufactured by Element Six and has a thickness of $0.68 \mathrm{~mm}$. Polycrystalline material has a range of technical uses, but it is extremely difficult to polish into anything resembling a traditional gemstone. Photo courtesy of Element Six Ltd.

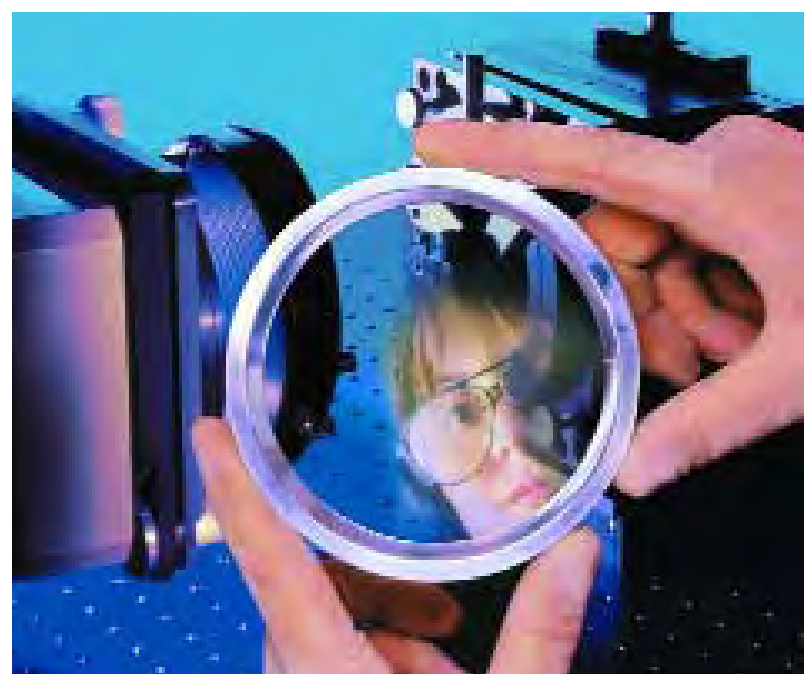

noted above-both Butler et al. (2002) and Wang et al. (2003) presented results of investigations of faceted material produced by Apollo Diamond. Isberg et al. (2002) reported measurements on single-crystal CVD synthetic diamond produced by Element Six that indicated dramatic improvements in the electronic properties, suggesting that this material may have a future in electronic devices. For the remainder of this article, the term CVD synthetic diamond should be understood to refer to single-crystal CVD synthetic diamond.

\section{MATERIALS AND METHODS}

Materials. There are many process variables that can influence the properties of the CVD material produced. Over the last 15 years, researchers at Element Six have varied the growth process in many different ways to gain a general understanding of the relationship between growth conditions and material properties. The results reported here have been gathered from studies of over a thousand CVD synthetic diamond samples grown by Element Six since the early 1990s as part of the Diamond Trading Company's proactive research program aimed at identifying methods to distinguish CVD synthetics from natural diamond. This research has focused on developing an understanding of how growth conditions affect the properties of the material produced, particularly those that can be useful for identifying CVD synthetic diamond.

The single-crystal CVD synthetic samples for which results are presented here were grown on single-crystal diamond substrates (predominantly HPHT-grown synthetics) processed into plates with the dominant faces being within a few degrees of a cube $\{100\}$ plane. They may be divided into four categories. First, several hundred samples were grown with nitrogen added to the growth process; for many of these, the nitrogen concentration in the process gases was altered during growth to investigate the effect of such changes. Approximately 50 of these Ndoped samples, which were predominantly brown, were given high pressure/high temperature treatments in a belt-type press, under diamond stable conditions, to investigate the effect on their color and other properties. Samples belonging to the third category were grown with small concentrations of diborane $\left(\mathrm{B}_{2} \mathrm{H}_{6}\right)$, a source of boron, added to the growth gases in order to produce boron-doped material. The focus of our research has been on looking for any weaknesses in detection methodologies, and 

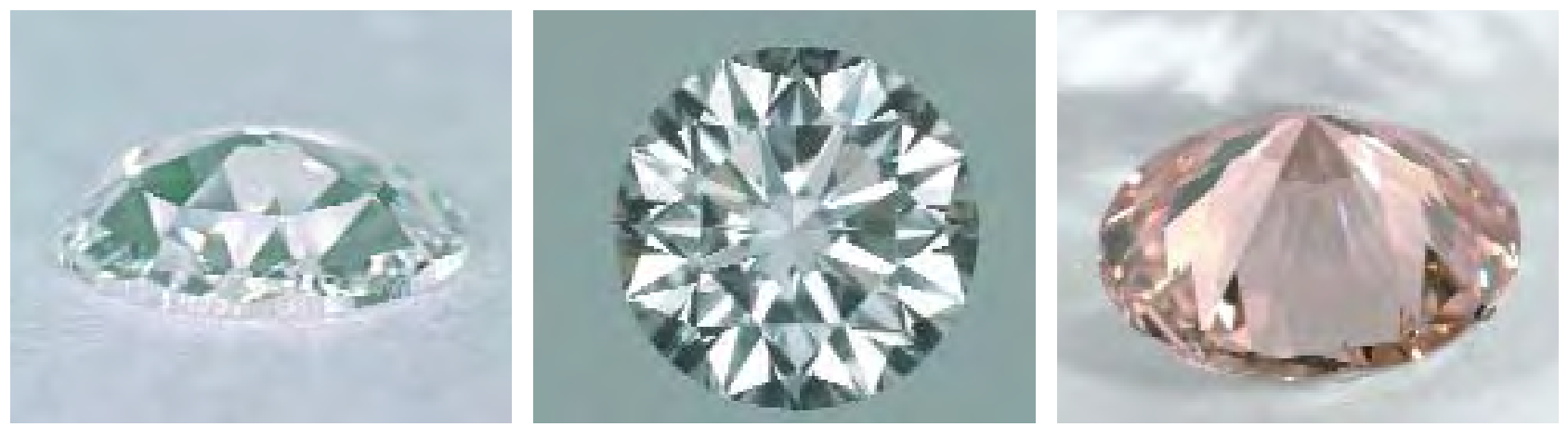

Figure 4. High-purity CVD material is colorless, as illustrated by the $0.44 \mathrm{ct}\left(D-S I_{1}\right)$ rose cut and $0.82 \mathrm{ct}\left(E-V V S_{1}\right)$ round brilliant shown here (left and center), but it is technically more difficult to grow than brown material, such as the $0.85 \mathrm{ct}$ pinkish brown $\left(V V S_{1}\right)$ round brilliant on the right. For relatively thin layers of CVD synthetic diamond, flat cuts give the highest yield, but the ability to grow thicker layers makes brilliant cuts more feasible. Photos by M. Crowder and P. Martineau.

we have therefore moved our process in directions that remove potential detection features. Thus, for the final category of samples, strenuous efforts were made to eliminate all sources of nitrogen and boron impurities from the growth process to produce colorless CVD material of high purity. We believe that categorizing the material we have grown in terms of impurities will bring out the most relevant information for gemologists.

Various samples were processed in three principal ways. More than 200 samples were polished as free-standing CVD plates from which the substrate was removed. Approximately 200 polished crosssectional slices through CVD layers and their substrates were also produced. Twenty-seven samples were faceted in order to test proposed detection

Figure 5. This 1.03 ct Fancy Deep blue square-cut $C V D$ synthetic $\left(V S_{2}\right.$ clarity, type IIb) was grown with diborane added to the process gases. Photo by $M$. Crowder.

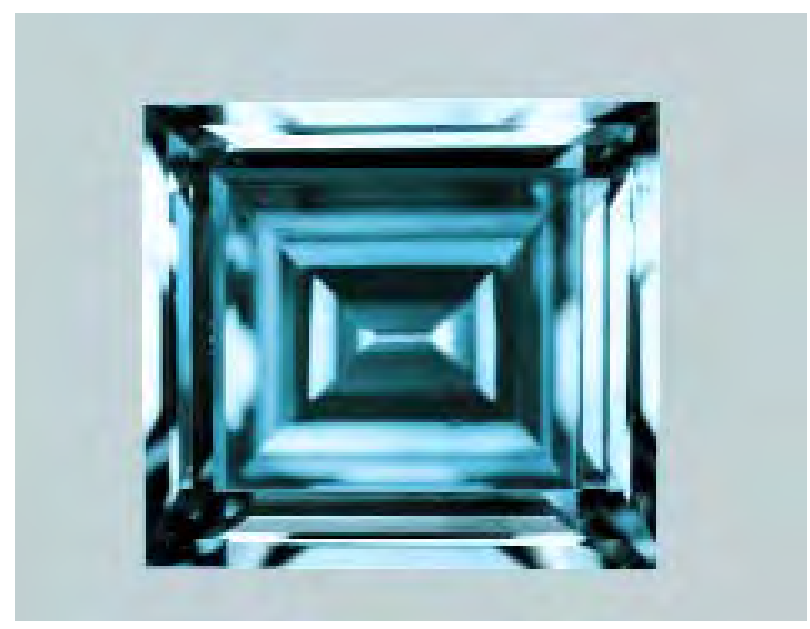

methods, give information on the grades that are achievable for various kinds of CVD synthetic material, and help educate gemologists. The faceted samples ranged from 0.21 to $2.64 \mathrm{ct}$ and, with the exception of those produced from boron-doped CVD material, from colorless to dark brown (see, e.g., figures 1 and 4). B-doped faceted samples ranged from light blue to intense blue (see, e.g., figure 5).

Methods. Birefringence microscopy was carried out for all the free-standing plates and cross-sectional slices with a Wild M420 microscope equipped with a pair of polarizers.

X-ray topographs (Lang et al., 1992) were recorded, with a $0.25 \mathrm{~mm}$ slit width, on Ilford L4 nuclear emulsion using Mo $\mathrm{K} \alpha_{1}$ radiation (wavelength: $0.070926 \mathrm{~nm}$ ) from a Marconi GX20 rotating anode $\mathrm{X}$-ray generator. With this wavelength, use of the $<533>$ reflection allowed diamond samples to be set up so that the plane sampled by the X-ray beam was very close to a cube $\{100\}$ plane. It also allowed topographs to be recorded with relatively little projection distortion because, at $81.37^{\circ}, 2 \theta$ for the Bragg condition was fairly close to $90^{\circ}$. We recorded X-ray

TABLE 1.Laser and spectrometer systems used in Raman and photoluminescence studies of CVD synthetic diamond.

\begin{tabular}{|c|c|c|}
\hline Wavelength & Laser & Spectrometer system \\
\hline 325 nm & $\mathrm{HeCd}(60 \mathrm{~mW})$ & $\begin{array}{l}\text { JY Horiba Labram } \\
\text { Raman system }\end{array}$ \\
\hline $\begin{array}{l}488 \mathrm{~nm} \text { and } \\
514 \mathrm{~nm}\end{array}$ & Ar ion $(300 \mathrm{~mW})$ & Spex 1404 \\
\hline 633 nm & $\mathrm{HeNe}(27 \mathrm{~mW})$ & $\begin{array}{l}\text { JY Horiba Labram } \\
\text { Raman system }\end{array}$ \\
\hline $785 \mathrm{~nm}$ & NIR diode $(25 \mathrm{~mW})$ & $\begin{array}{l}\text { Renishaw } 1000 \\
\text { Raman system }\end{array}$ \\
\hline
\end{tabular}




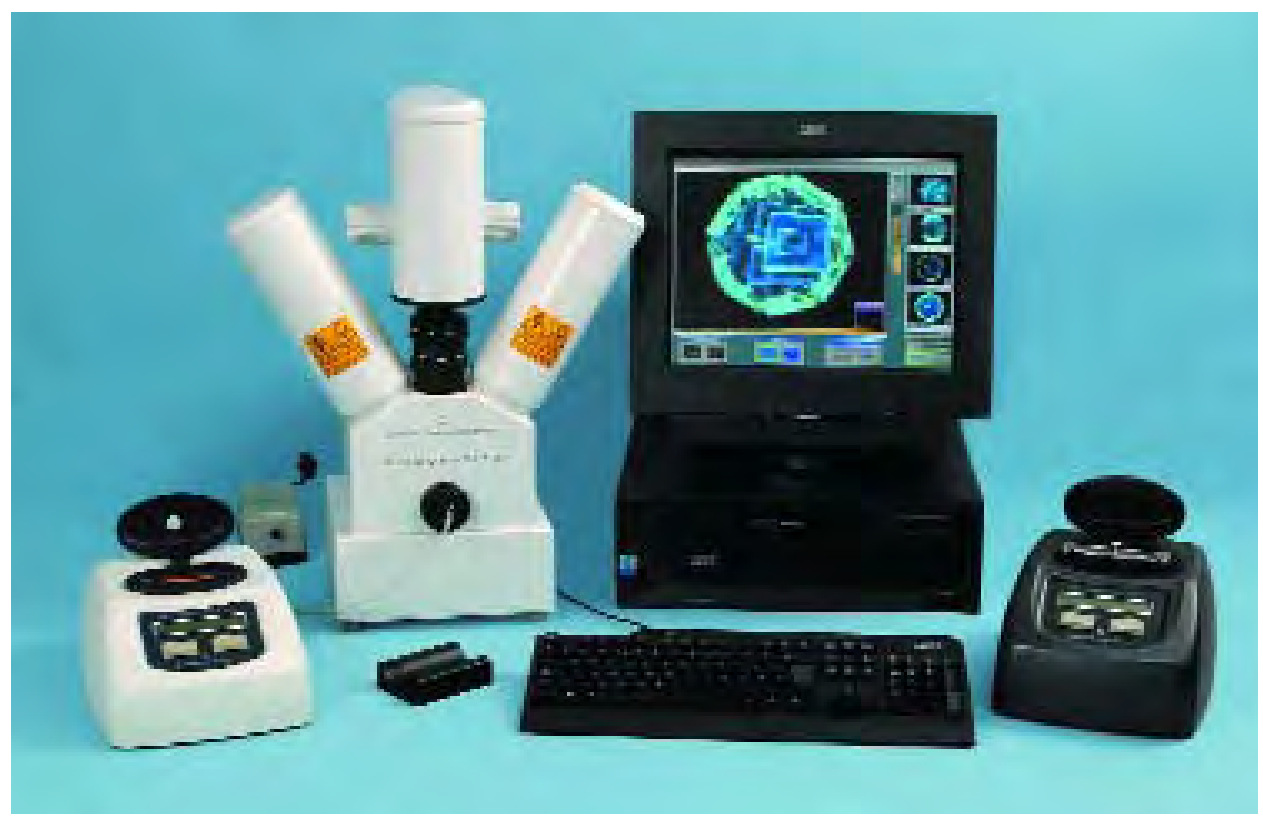

Figure 6. The Diamond

Trading Company's

Diamond Verification

Instruments are effec-

tive for identifying both

HPHT-grown and CVD

synthetics. From left to

right, this picture shows

the DiamondSure,

DiamondView, and

DiamondPLus instru-

ments. Photo by $C$.

Alderman.

topographs for approximately 150 CVD synthetic diamond samples (both faceted and unfaceted). Of these, approximately a hundred were nitrogendoped, 20 were boron-doped, and 30 were of high purity. We recorded X-ray topographs in such a way that the beam sampled a cross-sectional slice through the CVD layer and its substrate, using the $<533>$ X-ray reflection. We also obtained $<533>$ Xray section topographs parallel and perpendicular to the growth direction for faceted synthetic samples.

Absorption spectra were recorded for almost all the free-standing plates and many of the cross-sectional slices. Perkin Elmer Lambda 9 and Lambda 19 spectrometers were used to record absorption spectra in the ultraviolet, visible, and near-infrared regions of the spectrum. A Nicolet Magna-IR 750 FTIR spectrometer was used to cover the range between $11,000 \mathrm{~cm}^{-1}$ and $400 \mathrm{~cm}^{-1}$.

Photoluminescence and Raman spectra were recorded for five different laser excitation wavelengths (table 1). At each wavelength of excitation, at least 10 samples were investigated for each of the four categories of CVD synthetic diamond material mentioned above. Observations of luminescence excited by ultraviolet radiation were made for all of the faceted stones in a darkened room using conventional long-wave $(365 \mathrm{~nm})$ and short-wave (254 nm) Ultraviolet Products lamps.

Cathodoluminescence (CL) topographs were recorded using a CLmk4 (Cambridge Image Technology Ltd.) and a Wild M420 microscope equipped with a digital camera. CL spectra were recorded using a Cambridge Instruments 336 SEM equipped with an Oxford Instruments MonoCL spectrometer. For each of the four categories of CVD synthetic diamond material mentioned above, at least 10 samples were investigated using CL topography and spectroscopy.

All of the faceted stones were tested on all three Diamond Trading Company Diamond Verification Instruments (figure 6). Earlier versions of DiamondSure and DiamondView, which were developed for identification of HPHT-grown synthetics, were described in a Gems $\nrightarrow$ Gemology article by Welbourn et al. (1996) and are in use in gemological laboratories worldwide. These instruments have now been significantly improved and are commercially available from GIA Instruments UK Ltd. A third instrument, DiamondPLus, has been developed to help with the detection of HPHT-treated type II diamond (Welbourn and Williams, 2002).

DiamondSure is a compact instrument that produces a "Pass" or "Refer" result on the basis of an absorbance measurement across the visible and ultraviolet regions of the spectrum. "Pass" indicates that the stone is a natural diamond that requires no further testing. "Refer" means that further testing is required to determine whether the stone is synthetic or natural. Tests on more than 300,000 natural diamonds and several hundred HPHT-grown synthetic diamonds have indicated that DiamondSure refers only $1-2 \%$ of natural diamonds, but it refers all HPHT-grown synthetics.

Photoluminescence (PL) images were recorded with a DiamondView that has been improved in a number of ways that will be detailed in a future article. This instrument exposes polished stones to shortwave UV radiation and records a digital image of the resulting surface luminescence. It may also be used to 

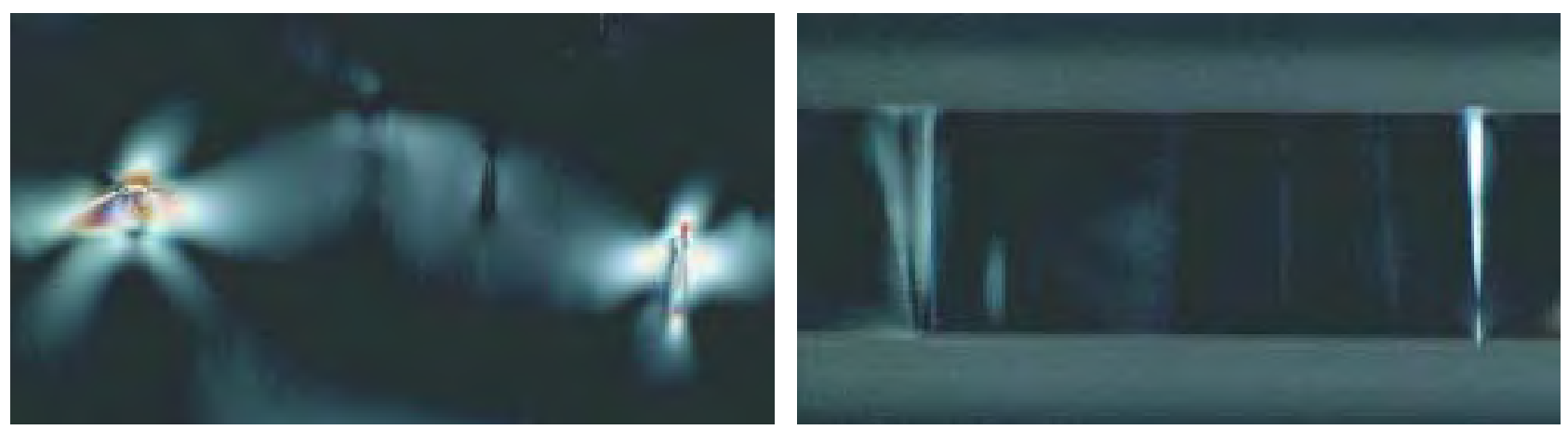

Figure 7. These photomicrographs of a free-standing tabular plate of CVD synthetic diamond (1.06 mm thick) were recorded with crossed-polarizers in a viewing direction parallel (left) and perpendicular (right) to the growth direction. The optical path lengths were $1.06 \mathrm{~mm}$ and $4.02 \mathrm{~mm}$, respectively. The regions of anomalous birefringence run through the sample in a direction parallel to the growth direction. Such birefringence is believed to result when bundles of dislocations nucleate at or near the interface with the substrate and propagate in the growth direction as the layer grows. Photos by A. Taylor.

record phosphorescence images. The DiamondView was used to investigate the spatial distribution of both PL and phosphorescence for all but a small number of the samples produced for this study.

The new DiamondPLus is a compact instrument designed to make high-sensitivity, low-temperature photoluminescence measurements on polished stones immersed in liquid nitrogen. It contains two solid-state lasers and two miniature spectrometers. Each measurement takes about 20 seconds, and a result is then displayed on the screen.

\section{RESULTS}

Most of our results are presented under headings of the four main categories of CVD synthetic diamond material that we investigated. We start, however, with two general sections. The first describes results relating to gemological features that we observed using microscopy in some samples from each of the four varieties of material. It is important to stress, however, that many of the samples we investigated showed none of these features. The second summarizes results from X-ray topography studies in which characteristic contrast features were seen for all the samples in all four categories that we investigated.

General Gemological Features. Birefringence. The samples of CVD synthetic diamond we investigated often showed characteristic birefringence features. The photomicrographs in figure 7 show views of a free-standing plate of CVD synthetic diamond, with six cube $\{100\}$ faces, seen with crossed polarizers from perpendicular directions. Characteristic birefringence features showing higher-order colors can be seen in the micrograph recorded with the view- ing direction parallel to the growth direction. The strongest birefringence occurs with this viewing direction even though it gives the shortest path length. From the cross-sectional view, it can be seen that the corresponding regions of strain run all the way through the sample along the growth direction.

Figure 8. In this X-ray section topograph of a 2-mmthick layer of CVD synthetic diamond on a type $\mathrm{Ib}$ HPHT-grown synthetic substrate, a cross-sectional slice parallel to the growth direction has been sampled. The columnar texture is caused by dislocations and is typical of CVD synthetic diamond, but it is not always seen in such an extreme form. The interface between the substrate and the CVD layer is clearly evident from the abrupt change in contrast. Features such as these in X-ray topographs may be used as evidence to support identification.

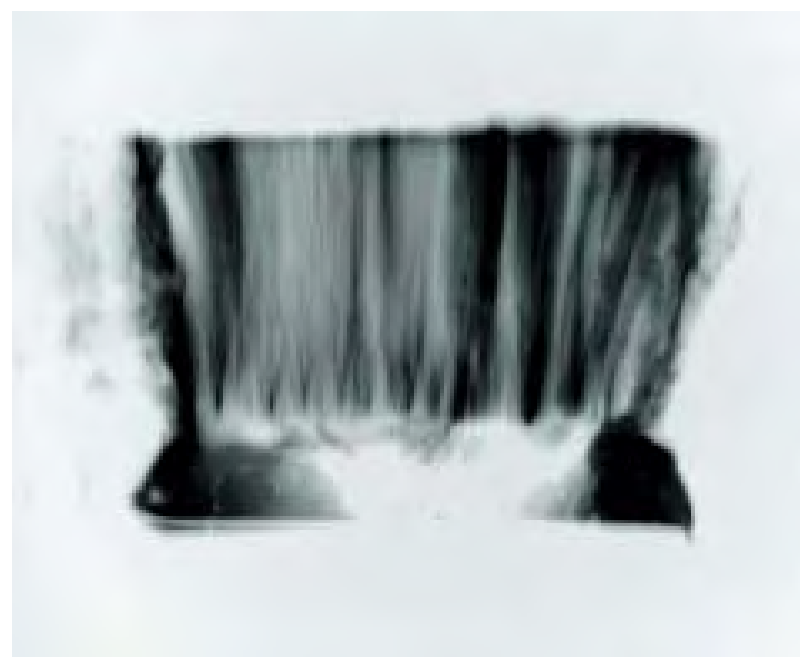


Crystallographic Orientation. We have found that, in CVD processes, growth on octahedral $\{111\}$ faces is problematic because there is a tendency for twins to form. Regions of samples that contained one or more twins were difficult to polish, had a tendency to crack, and were generally of lower optical quality. Most of the CVD synthetic diamond material that we investigated was grown on substrates with faces in near-cubic orientation, and octahedral growth faces had a tendency to form at the four corners. The resulting four regions of lower-quality diamond often limited the yield and clarity grade of faceted stones. Cracks, graphitic inclusions, or poor surface finish were sometimes seen in one or more of the four positions, typically near the girdle.

Layers with Different Colors. In many of the samples we investigated, we observed layers with different colors. When present, such layers were easily seen in cross-sectional slices or free-standing plates with polished faces. They were more difficult to discern for faceted CVD synthetic stones. In our experience, layers with different brown colors were most common but, for samples doped with boron, we also observed layers with different blue colors. For the most part, such layers formed parallel to the plane presented by the substrate, with deviations near the edges resulting from the formation of additional growth faces.

Figure 9. The columnar texture is also evident in this $X$-ray section topograph of a faceted CVD synthetic (girdle diameter $5.5 \mathrm{~mm}$ ), in which a cross-sectional slice parallel to the growth direction was sampled by the $X$-ray beam.

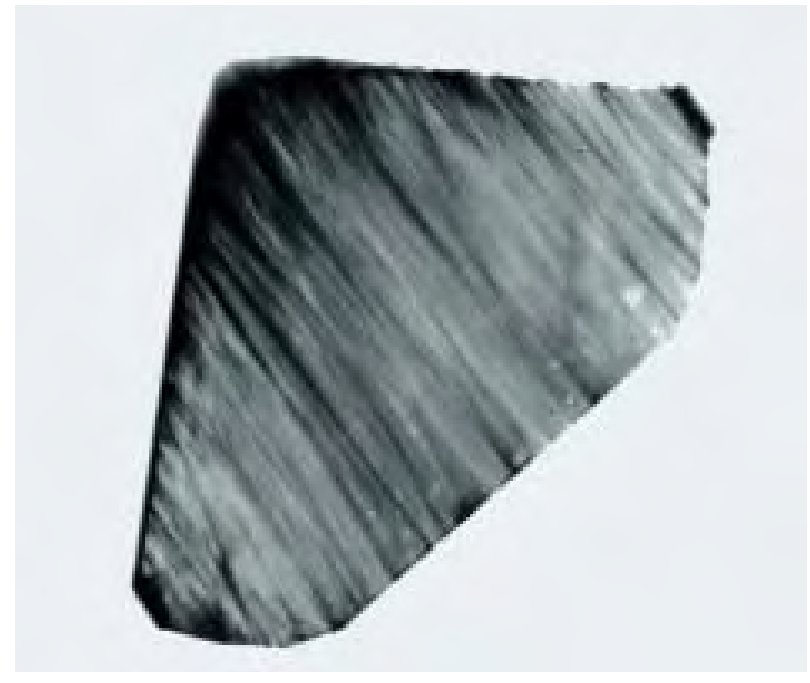

Inclusions. We observed inclusions in only a few of our samples. In those rare cases, for the most part they appeared as groups of pinpoint inclusions lying in planes parallel to the interface between the CVD layer and the substrate on which it was grown. On the basis of Raman scattering, these pinpoint inclusions could generally be associated with non-diamond carbon.

X-ray Topography. X-ray topographs for samples from each of the four categories of CVD synthetic diamond material showed striking similarities, and the results are therefore reported together here. Cross-sectional topographs through a CVD layer and its substrate showed contrast features similar to those seen in figure 8, but not generally in such an extreme form. A change in contrast relating to the position of the interface between the substrate and the CVD layer was clearly visible. All the cross-sectional topographs recorded parallel to the growth direction showed contrast streaks similar to those observed in figure 9. Within each of the four categories of samples, the plan-view topographs revealed different kinds of contrast, ranging from the type of features seen in figure 10 to a more poorly defined cross-hatch pattern.

Figure 10. In this $X$-ray section topograph of the faceted CVD synthetic shown in figure 9, the $X$-ray beam sampled a plan-view slice through the girdle and perpendicular to the growth direction. The dark spots are believed to be caused by bundles of dislocations aligned close to perpendicular to the plane sampled by the X-ray beam.

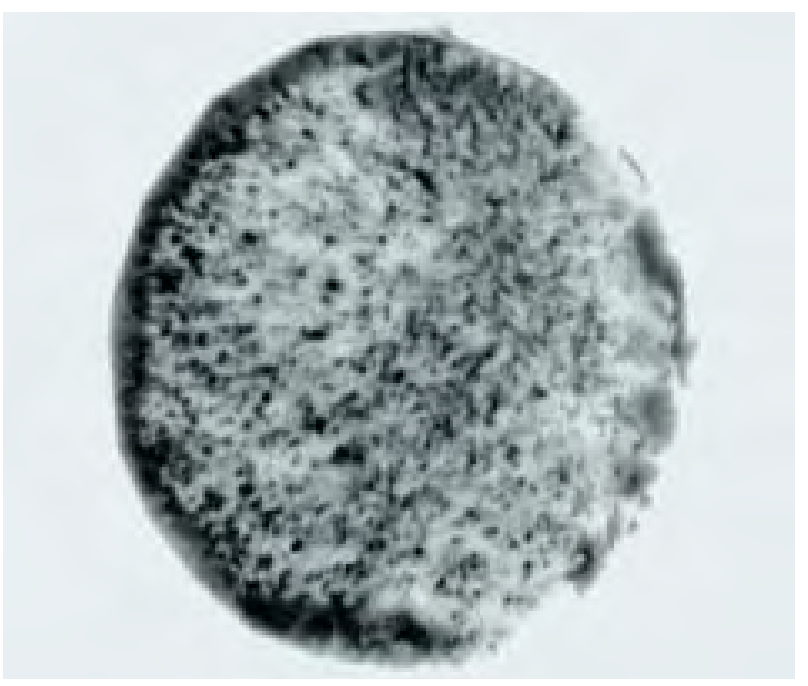




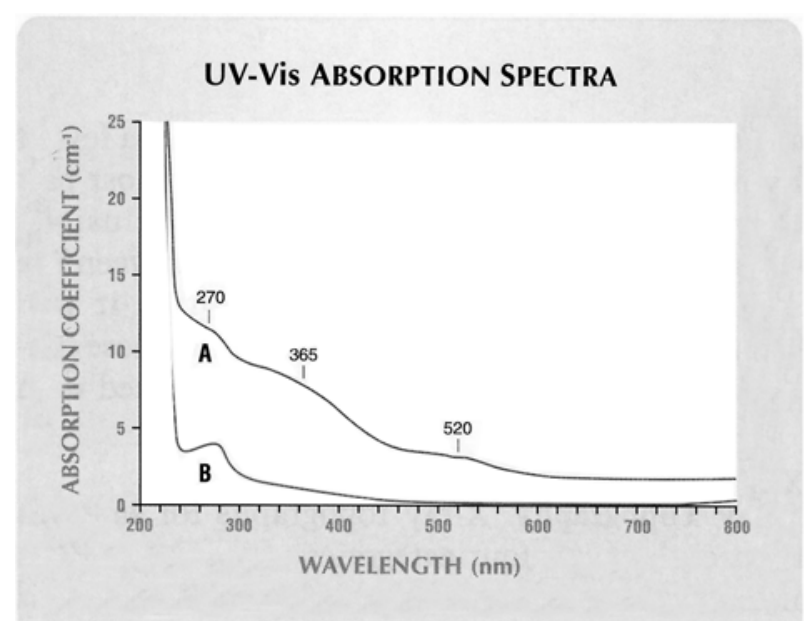

Figure 11. Absorption spectrum A, of an initially brown layer of nitrogen-doped CVD synthetic diamond, is typical of the spectra recorded at room temperature for this material. It shows broad features at $270 \mathrm{~nm}$ and approximately 365 and $520 \mathrm{~nm}$. After an HPHT treatment that removed the brown color from this same specimen, the spectrum (B) shows no evidence of the features at about 365 and $520 \mathrm{~nm}$.

Samples Grown with Added Nitrogen. After removal of their substrates, samples grown with added nitrogen were found to range from faint brown to dark brown (or black in extreme cases). For a given sample thickness, there was a strong correlation between the nitrogen concentration in the process gases and the saturation of the brown color. Moreover, when the nitrogen concentration in the process gases was changed during a growth run, examination of polished cross-sections produced from the samples grown showed that layers with different brown colors resulted, as described above. For most of the samples that we investigated, no nitrogen-related absorption could be detected in the one-phonon region of the infrared spectrum and the material was therefore classified as type II (for details of diamond classification by type, see Shigley et al., 1986). In rare cases, absorption features were observed at $1344 \mathrm{~cm}^{-1}$ and $1130 \mathrm{~cm}^{-1}$, indicating the presence of isolated nitrogen atoms (see, for example, Clark et al., 1992). In these rare cases, the material was classified as type Ib.

UV-visible absorption spectrum A in figure 11 was recorded at room temperature for a typical free-standing plate of CVD synthetic diamond grown with nitrogen added to the gas mixture. Broad features may be seen at $270 \mathrm{~nm}$ and approximately 365 and $520 \mathrm{~nm}$. In addition to these, there is a general rise in absorption coefficient toward shorter wavelengths. Table 2 lists features that we have observed in the optical absorption spectra of samples grown with added nitrogen. Many of these lines have been reported previously for samples produced by Apollo Diamond (Butler et al., 2002; Wang et al., 2003). However, we observed an additional absorption feature at $3323 \mathrm{~cm}^{-1}$ in the spectra of dark brown samples that was not reported by either of the above studies.

Figure 12 shows the photoluminescence spectrum of a brown CVD synthetic diamond sample excited at liquid nitrogen temperature with a 514 $\mathrm{nm}$ Argon ion laser. It exhibits PL systems with zero-phonon lines at 575 and $637 \mathrm{~nm}$ that were present in the spectra of all the nitrogen-doped samples we investigated. It also shows a pair of sharp lines at 596 and $597 \mathrm{~nm}$ that we have observed only for nitrogen-doped samples. Samples grown early in our research program showed a line at $737 \mathrm{~nm}$ /also reported for Apollo Diamond's CVD synthetic material [Wang et al., 2003]), but this feature was absent from the spectra of samples grown more recently.

Spectrum A in figure 13 is the PL spectrum of an as-grown nitrogen-doped CVD synthetic diamond sample excited using a $325 \mathrm{~nm} \mathrm{HeCd}$ laser at $77 \mathrm{~K}$. It shows lines at 467, 533, and $575 \mathrm{~nm}$. The $533 \mathrm{~nm}$ and $575 \mathrm{~nm}$ lines were observed for all nitrogen-doped

Figure 12. This photoluminescence spectrum of a nitrogen-doped CVD synthetic diamond sample, excited at $77 \mathrm{~K}$ with $514 \mathrm{~nm}$ argon ion laser radiation, shows zerophonon lines at 575 and $637 \mathrm{~nm}$. The spectrum also contains a pair of lines at 596 and $597 \mathrm{~nm}$. First reported by Wang et al. (2003), to the best of our knowledge these two lines have never been detected for natural diamond or HPHT-grown synthetic diamond.

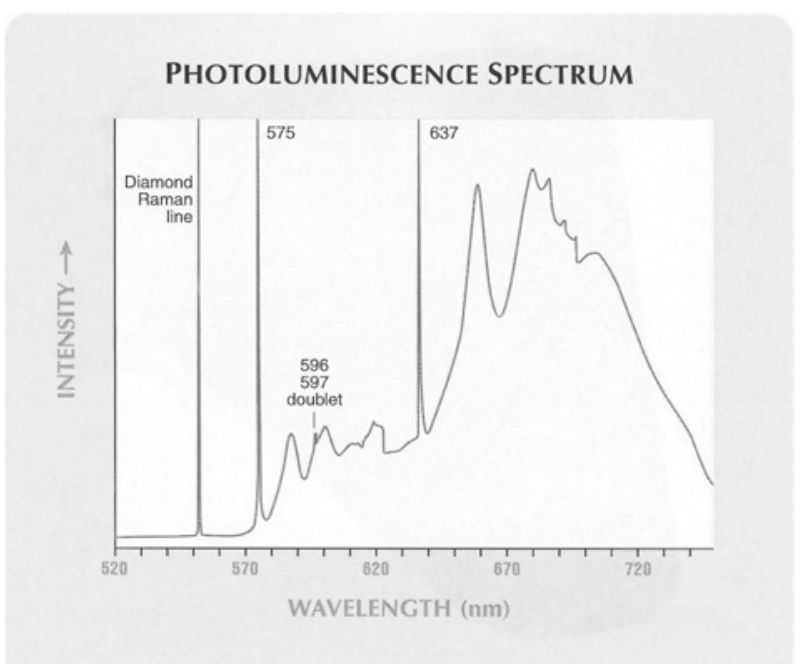


TABLE 2. Common features observed in the spectra of some as-grown and HPHT-treated nitrogen-doped CVD synthetic diamond, a,b

\begin{tabular}{|c|c|c|}
\hline Feature & Method & Notes/comments \\
\hline $270 \mathrm{~nm}$ & UV-Vis-NIR absorption spectroscopy & $\begin{array}{l}\text { Associated with isolated nitrogen; also seen in type Ib HPHT-grow syn- } \\
\text { thetic diamond and in some HPHT-treated type lla natural diamond. }\end{array}$ \\
\hline Ramp & UV-Vis-NIR absorption spectroscopy & $\begin{array}{l}\text { Gradual rise in absorbance toward shorter wavelengths. Seen across the } \\
\text { UV, visible, and NIR regions of the spectrum. Removed by HPHT trement. } \\
\text { A similar rise is sometimes seen in type lla natural diamond. }\end{array}$ \\
\hline $365 \mathrm{~nm}$ & UV-Vis-NIR absorption spectroscopy & $\begin{array}{l}\text { Broad band not seen in natural diamond or HPHT-grown synthetic dimono } \\
\text { Removed by HPHT treatment. }\end{array}$ \\
\hline $389 \mathrm{~nm}$ & $\begin{array}{l}\text { PL spectroscopy ( } 325 \mathrm{~nm} \text { excitation) } \\
\text { and CL spectroscopy }\end{array}$ & $\begin{array}{l}\text { Removed by HPHT treatment. Also seen in some HPHT-grown synthetic } \\
\text { diamond and in radiation-damaged N-containing diamond. }\end{array}$ \\
\hline $415 \mathrm{~nm}$ & $\begin{array}{l}\mathrm{CL} \text { and } \mathrm{PL} \text { spectroscopy } \\
\text { (325 nm excitation) }\end{array}$ & $\begin{array}{l}\text { HPHT-treated CVD synthetic diamond. N3 center associated with nitrogen; } \\
\text { also observed in natural diamond. }\end{array}$ \\
\hline $\begin{array}{l}451-459 \mathrm{~nm} \\
\text { series of lines }\end{array}$ & PL spectroscopy (325 nm excitation) & Observed only in HPHT-treated CVD synthetic diamond. \\
\hline $467 \mathrm{~nm}$ & $\begin{array}{l}\text { PL spectroscopy ( } 325 \mathrm{~nm} \text { excitation) and } \\
\text { CL spectroscopy }\end{array}$ & $\begin{array}{l}\text { Not seen in natural or HPHT-grown synthetic diamond; removed by HPHT } \\
\text { treatment. }\end{array}$ \\
\hline $503 \mathrm{~nm}$ & PL spectroscopy (325 nm excitation) & $\begin{array}{l}\text { HPHT-treated CVD synthetic diamond. H3 center associated with nitrogen; } \\
\text { also observed in some natural diamond and HPHT-grown synthetic diamond }\end{array}$ \\
\hline $520 \mathrm{~nm}$ & UV-Vis-NIR absorption spectroscopy & $\begin{array}{l}\text { Broad band not seen in natura diamond or HPHT-grown synthetic dimond } \\
\text { Removed by HPHT treatment. }\end{array}$ \\
\hline $533 \mathrm{~nm}$ & $\begin{array}{l}\text { PL spectroscopy ( } 325 \mathrm{~nm} \text { excitation) and } \\
\text { CL spectroscopy }\end{array}$ & $\begin{array}{l}\text { Not seen in natural or HPHT-grown synthetic diamond. Removed or sub- } \\
\text { stantially reduced by HPHT treatment. }\end{array}$ \\
\hline $575 \mathrm{~nm}$ & $\begin{array}{l}\text { PL spectroscopy ( } 325,488 \text {, and } 514 \mathrm{~nm} \\
\text { excitations) and CL spectroscopy }\end{array}$ & $\begin{array}{l}\mathrm{NV}^{0} \text { center; reduced but still readily detectable after HPHT treatment. } \\
\text { Also seen in some HPHT-grown synthetic diamond and some natural } \\
\text { type lla diamond. }\end{array}$ \\
\hline $596 \mathrm{~nm}$ & UV-Vis-NIR absorption spectroscopy & $\begin{array}{l}\text { Observed in absorption spectra of some brown CVD synthetic diamond } \\
\text { and not seen in natural diamond. Removed by HPHT treatment. Line- } \\
\text { width comparison indicates that this has a different origin from the } 596 \\
\mathrm{~nm} \text { PL line. }\end{array}$ \\
\hline $\begin{array}{l}596 / 597 \mathrm{~nm} \\
\text { doublet }\end{array}$ & $\begin{array}{l}\text { PL spectroscopy ( } 488 \text { and } 514 \mathrm{~nm} \\
\text { excitations) }\end{array}$ & $\begin{array}{l}\text { Narrow PL lines not seen in natural or HPHT-grown synthetic diamond. } \\
\text { Not observed after HPHT treatment. }\end{array}$ \\
\hline $625 \mathrm{~nm}$ & UV-Vis-NIR absorption spectroscopy & $\begin{array}{l}\text { Observed in some brown CVD synthetic diamond and not seen in natural } \\
\text { or HPHT-grown diamond. Removed by HPHT treatment. }\end{array}$ \\
\hline $637 \mathrm{~nm}$ & $\begin{array}{l}\text { UV-Vis-NIR absorption spectroscopy and } \\
\text { PL spectroscopy ( } 488 \text { and } 514 \mathrm{~nm} \\
\text { excitations) }\end{array}$ & $\begin{array}{l}\mathrm{NV}^{-} \text {center; seen in absorption and PL spectra of some natural and } \\
\text { HPHT-grown synthetic diamond. }\end{array}$ \\
\hline $737 \mathrm{~nm}$ & $\begin{array}{l}\text { UV-Vis-NIR absorption spectroscopy and } \\
\text { PL spectroscopy (488, 514, \& } 633 \mathrm{~nm} \\
\text { excitations) }\end{array}$ & $\begin{array}{l}\text { Si-related; not seen in more recently grown (Element Six) samples of CVD } \\
\text { synthetic diamond, and not seen in natural diamond; seen in HPHT-grown } \\
\text { synthetic diamond when silicon is deliberately added to the growth capsule } \\
\text { Not removed by HPHT treatment. }\end{array}$ \\
\hline $\begin{array}{l}8753,7354 \\
6856,6524 \\
5564 \mathrm{~cm}^{-1}\end{array}$ & FTIR (or NIR) absorption spectroscopy & $\begin{array}{l}\text { H-related; not seen in natural or HPHT-grown synthetic diamond. Removed } \\
\text { by HPHT treatment. }\end{array}$ \\
\hline $3323 \mathrm{~cm}^{-1}$ & FTIR absorption spectroscopy & $\begin{array}{l}\text { H-related; seen in some brown CVD synthetic diamond. Not seen in natural } \\
\text { or HPHT-grown material. Removed by HPHT treatment. }\end{array}$ \\
\hline $3123 \mathrm{~cm}^{-1}$ & FTIR absorption spectroscopy & $\begin{array}{l}\text { H-related; not seen in natural or HPHT-grown synthetic diamond. } \\
\text { Removed by HPHT treatment. }\end{array}$ \\
\hline $3107 \mathrm{~cm}^{-1}$ & FIIR absorption spectroscopy & H-related. Appeared after HPHT treatment. Seen in some natural diamond. \\
\hline $2800-3000 \mathrm{~cm}^{-1}$ & FTIR absorption spectroscopy & $\begin{array}{l}\text { C-H stretch vibrational modes (see, for example, Fuchs et al. [1995]); not } \\
\text { seen in natural diamond and rarely seen in HPHT-grown synthetics. }{ }^{\circ}\end{array}$ \\
\hline $1540 \mathrm{~cm}^{-1}$ & Raman/PL spectroscopy (785 nm excitation) & Non-diamond carbon; removed by HPHT treatment. \\
\hline
\end{tabular}

aNone of these features is present in the spectra of all CVD synthetic diamond, and it is possible to grow CVD synthetic material that does not show any of these features.

${ }^{b}$ More information on many of these spectroscopic features is given by Zaitsev (2001).

cAll type Illb diamond, whatever its origin, shows B-related lines at 2802 and $2928 \mathrm{~cm}^{-1}$. For a typical example, see King et al. (1998), p. 252.

samples. The $467 \mathrm{~nm}$ line was observed for some, but not all, nitrogen-doped samples. When present in the PL spectrum of a sample, the lines at 467,533 , and $575 \mathrm{~nm}$ were also observed in the cathodolumines- cence spectrum. Table 2 also lists the PL features observed most commonly for the nitrogen-doped CVD synthetic diamond samples we studied. Cross-sectional slices through layers on HPHT- 


\section{PHOTOLUMINESCENCE SPECTRA}

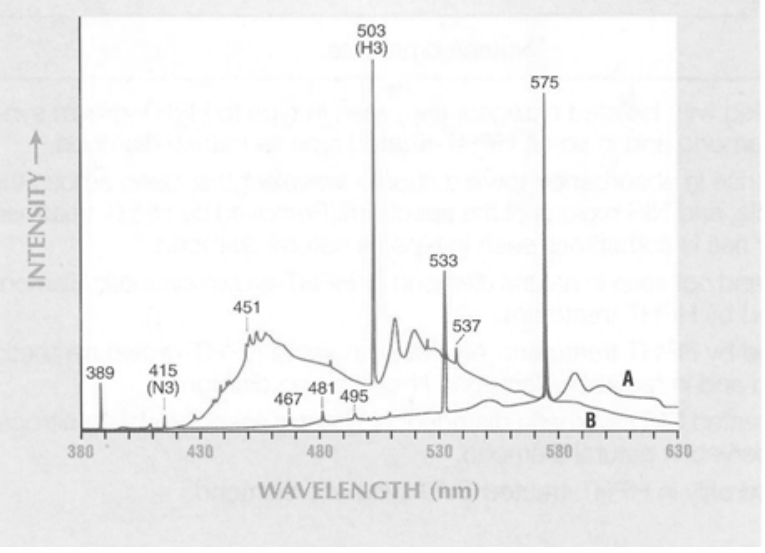

Figure 13. These photoluminescence spectra, excited at $77 \mathrm{~K}$ using $325 \mathrm{~nm} \mathrm{HeCd}$ laser radiation, were collected from an initially brown $N$-doped CVD synthetic diamond sample. Spectrum A, of the as-grown sample, shows zero-phonon lines at 467 and $533 \mathrm{~nm}$, which to the best of our knowledge have never been detected for natural or HPHT-grown synthetic diamond. These are also commonly seen in the cathodoluminescence spectrum of CVD synthetic diamond. Spectrum B, recorded after HPHT treatment removed the sample's brown color, shows $H 3$ and N3 luminescence at 503 and $415 \mathrm{~nm}$, respectively. It also shows a group of features between 451 and $459 \mathrm{~nm}$ that we believe have not been previously reported.

grown type Ib substrates showed clear color zoning (see figure 14, left). Orange to orangy red luminescence was observed in the DiamondView images of all the nitrogen-doped samples that we investigated (see, e.g., figure 14, right). In addition, all samples were observed to have striations (which run diagonally in figure 14, right) that were seen most easily in cross-sectional slices. In some samples, the striations were spaced too closely to be visible in the DiamondView images, but they were always evident in CL topographs recorded at higher magnification. The spacing between striations was fairly constant within a given sample, but it ranged from approximately $0.001 \mathrm{~mm}$ to $0.2 \mathrm{~mm}$ between samples.

The growth surface of nitrogen-doped samples invariably showed sequences of growth steps with terrace regions separated by inclined risers. There was a correspondence between the striation spacing for a given sample and the spacing between steps that formed on the growth surface during the CVD process. When traced to the growth surface, the striations observed in cross-sectional slices were found to terminate at the risers and terraces of such growth steps. Figure 15 illustrates schematically how these striations are formed.

Table 3 lists the weight, color, and clarity grades (as determined in our laboratory using the GIA grading scales) and fluorescence to long- and short-wave UV of our 14 faceted nitrogen-doped CVD synthetics. All the samples tested with the DiamondSure gave a "Refer" result. In the DiamondView, all those tested showed orange to orangy red luminescence. In eight cases, striations were observed in the DiamondView images (figure 16). In all cases, the 575 and $637 \mathrm{~nm}$

Figure 14. Color zoning is obvious in this polished cross-sectional slice through a CVD synthetic diamond layer on its HPHT-grown synthetic substrate (left). Although predominantly yellowish green, the type Ib HPHT-grown substrate has two sectors with less color. The sample is $6 \mathrm{~mm}$ long, and CVD growth beyond the edges of the substrate has been removed. In a DiamondView image of the same slice (right), the CVD layer shows the orange to orangy red luminescence typically seen for $N$-doped samples, as well as the characteristic striations (the circular pattern is from the vacuum holder). These striations are a result of different uptake of defects on the risers and terraces of steps on the growth surface. Photos by A. Taylor.
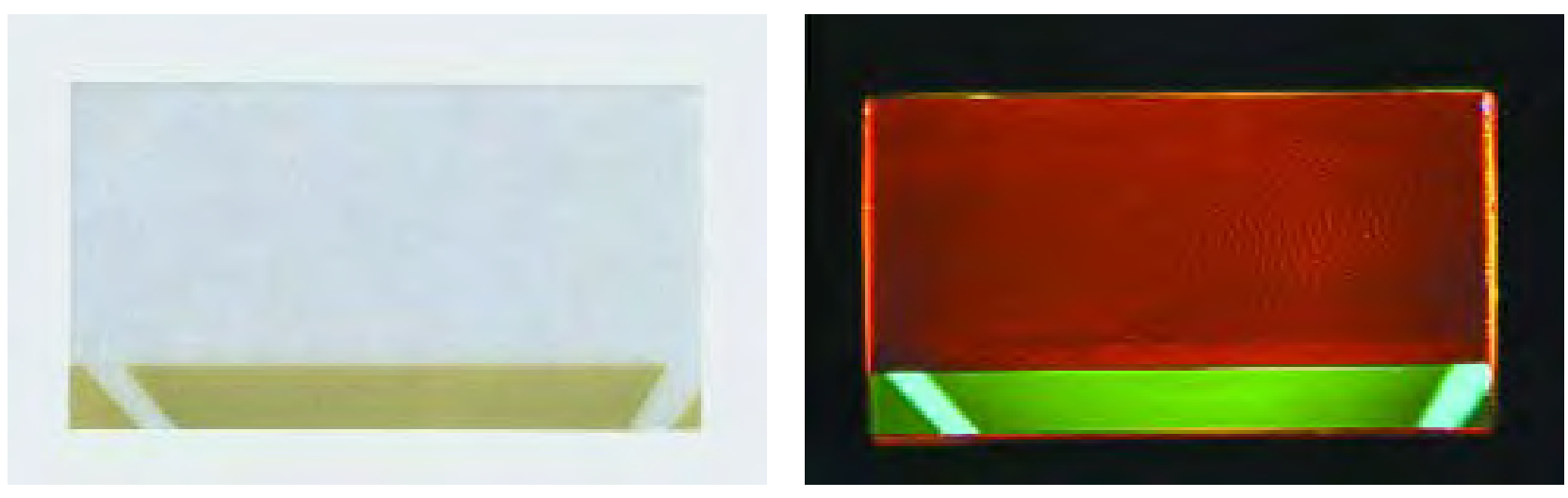


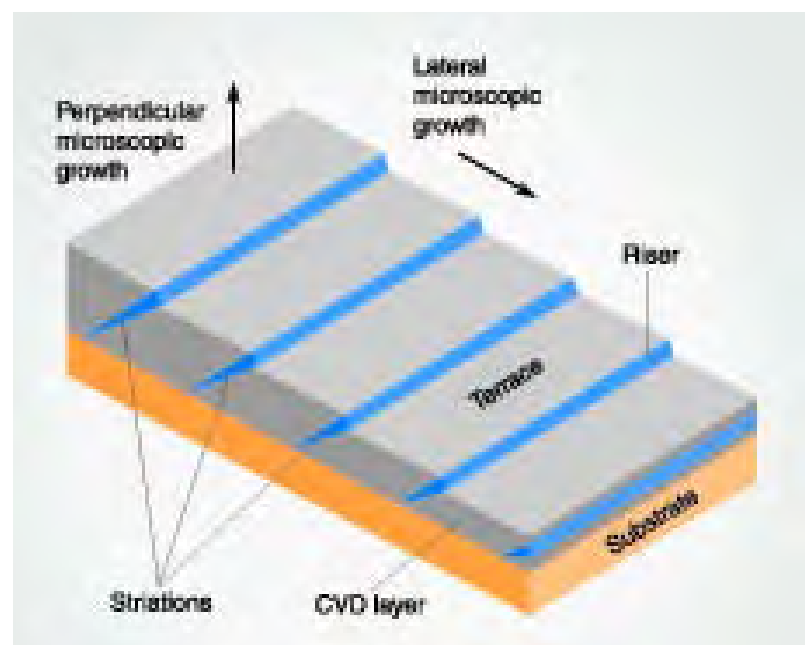

Figure 15. This schematic diagram shows part of a CVD synthetic diamond layer polished to reveal cross-sectional views. It illustrates the early development of striations caused by differential uptake of impurity-related defects on the risers and terraces (here blue and gray, respectively) of surface steps.

luminescence features were observed in PL spectra excited at $77 \mathrm{~K}$ with a $514 \mathrm{~nm}$ argon ion laser and were also detected by the DiamondPLus.

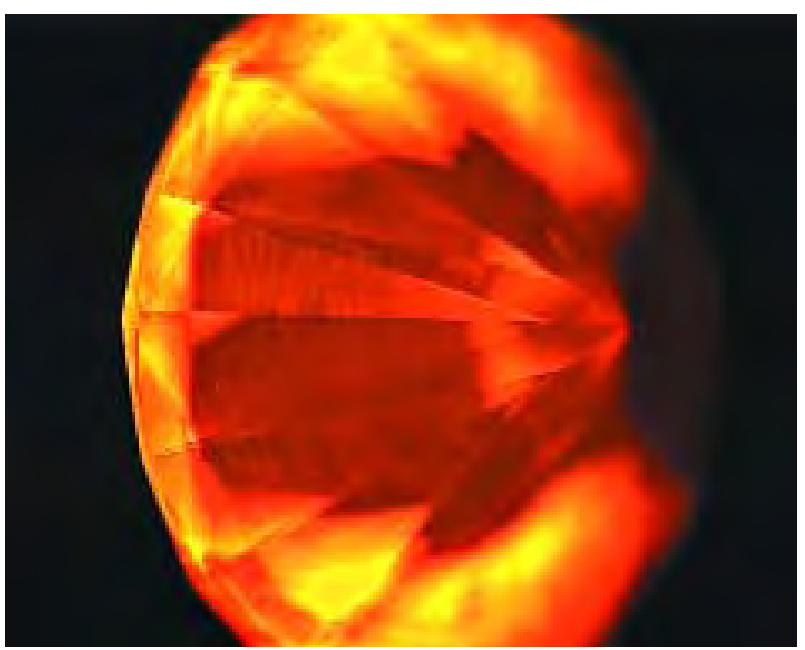

Figure 16. The orange luminescence and striations were also seen in the faceted CVD synthetics, as evident in this DiamondView image of a $0.85 \mathrm{ct} C V D$ synthetic round brilliant. Photo by $P$. Martineau.

HPHT-Treated CVD Synthetic Diamond. In all the cases investigated, UV-visible absorption spectroscopy revealed that HPHT treatment of brown nitrogen-doped CVD synthetic diamond under diamond stable conditions reduced the overall

\begin{tabular}{|c|c|c|c|c|c|c|}
\hline \multirow{2}{*}{$\begin{array}{l}\text { Sample } \\
\text { humber }\end{array}$} & \multirow{2}{*}{$\begin{array}{l}\text { Carat } \\
\text { weight }\end{array}$} & \multirow{2}{*}{ Cut } & \multirow{2}{*}{ Color } & \multirow{2}{*}{ Clarity } & \multicolumn{2}{|c|}{ UV fluorescence } \\
\hline & & & & & Long-wave & Short-wave \\
\hline $\mathrm{N} 1$ & 0.63 & Round brilliant & Brown & $\mathrm{I}_{1}$ & Weak orange & Weak orange \\
\hline N2 & 0.90 & Round brilliant & $\begin{array}{l}\text { Fancy pinkish } \\
\text { brown }\end{array}$ & $I_{3}$ & Orange & Orange ${ }^{a}$ \\
\hline N3 & 0.34 & Square cut & $\mathrm{G}$ & $\mathrm{VS}_{1}$ & Weak orange & Weak orange \\
\hline N4 & 0.50 & Square cut & $\mathrm{H}$ & $\mathrm{VS}_{2}$ & Weak orange & Weak orange \\
\hline N5 & 1.04 & Square cut & $\begin{array}{l}\text { Fancy Dark } \\
\text { brown }\end{array}$ & $\mathrm{SI}_{1}^{2}$ & Orange & Orange $^{a}$ \\
\hline N6 & 1.10 & Square cut & $\begin{array}{l}\text { Fancy Light } \\
\text { pinkish brown }\end{array}$ & $\mathrm{VS}_{1}$ & Orange & Orange $^{a}$ \\
\hline N7 & 1.04 & Square cut & $\begin{array}{l}\text { Fancy pinkish } \\
\text { brown }\end{array}$ & $I_{1}$ & Orange & Orange $^{a}$ \\
\hline N8 & 0.85 & Round brilliant & $\begin{array}{l}\text { Fancy brownish } \\
\text { pink }\end{array}$ & $\mathrm{VVS}_{1}$ & Orange & Orange ${ }^{a}$ \\
\hline N9 & 0.50 & Square cut & $\begin{array}{l}\text { Fancy Light } \\
\text { pinkish brown }\end{array}$ & $\mathrm{VS}_{1}$ & Orange & Orange \\
\hline N10 & 0.38 & Emerald cut & $\begin{array}{l}\text { Fancy Light } \\
\text { pinkish brown }\end{array}$ & $\mathrm{VVS}_{1}$ & Orange & Orange \\
\hline N11 & 0.50 & Round brilliant & Brown & $\mathrm{VS}_{1}$ & Weak orange & Weak orange ${ }^{a}$ \\
\hline N12 & 0.55 & Round brilliant & Brown & $\mathrm{SI}_{2}$ & Weak orange & Weak orange ${ }^{a}$ \\
\hline N13 & 0.39 & Princess cut & Brown & $\mathrm{SI}_{1}$ & Weak orange & Weak orange ${ }^{a}$ \\
\hline N14 & 2.23 & $\begin{array}{l}\text { Rectangular } \\
\text { step cut }\end{array}$ & Pinkish brown & $\mathrm{I}_{1}$ & Orange & Orange \\
\hline
\end{tabular}

astriations were observed in DiamondView images of these samples. 

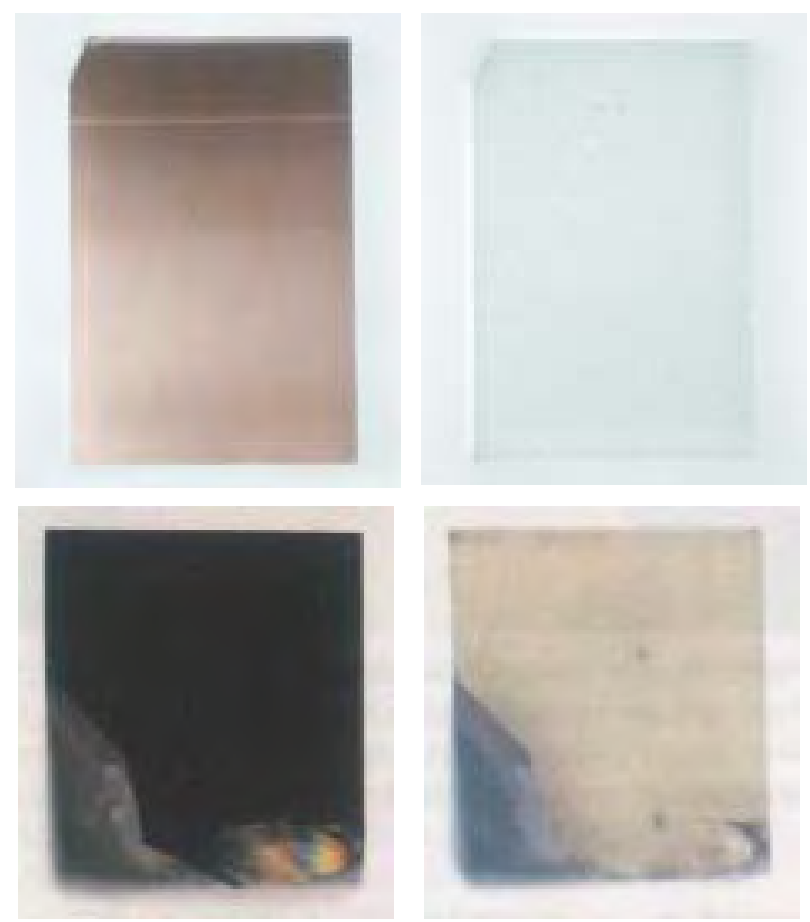

Figure 17. These photographs illustrate how two Ndoped CVD synthetic diamond samples that started as brown (top left, $3.06 \times 2.06 \times 0.86 \mathrm{~mm}^{3}$ ) and black (bottom left, $1.52 \times 1.34 \times 0.94 \mathrm{~mm}^{3}$ ) responded to HPHT treatment (right). Photos by A. Taylor.

absorption in the visible and ultraviolet regions of the spectrum. All of these samples showed a corresponding reduction or change in color. Figure 17 shows how HPHT treatment affected the color of two samples: one brown and the other black. After treatment, the brown sample was nearly colorless and the black sample had become a pale greenish brown.

We recorded UV-visible absorption spectra for the same region of a brown sample before and after HPHT treatment (again, see figure 11). Note that the broad features at approximately $365 \mathrm{~nm}$ and $520 \mathrm{~nm}$ were removed by the treatment, and there was also a substantial reduction in the general rise in absorption toward shorter wavelengths. The shape of the post-treatment spectrum is very similar to that for the absorption caused by a low concentration of isolated nitrogen atoms.

HPHT treatment of brown CVD synthetic samples also caused a change in the hydrogen-related features in their infrared absorption spectra (again, see table 2). For example, it removed the hydrogenrelated absorption lines in the near-infrared region of the spectrum and at $3123 \mathrm{~cm}^{-1}$ and $3323 \mathrm{~cm}^{-1}$. In most cases, a hydrogen-related line at $3107 \mathrm{~cm}^{-1}$, seen in the absorption spectra of some natural diamonds (Woods and Collins, 1983), was observed after HPHT treatment.

We also recorded Raman/photoluminescence spectra (at room temperature, with $785 \mathrm{~nm}$ excitation; figure 18) for the same region of a sample before and after HPHT treatment that substantially reduced the absorption in the visible and ultraviolet regions. The feature at approximately $1540 \mathrm{~cm}^{-1}$ in the spectrum recorded before treatment indicates the presence of non-diamond carbon. The spectrum of the post-treatment sample contains only the diamond Raman line and shows no evidence of non-diamond carbon.

Figure 13 shows PL spectra for this sample as recorded at liquid nitrogen temperature with 325 $\mathrm{nm}$ excitation before and after HPHT treatment. Although substantially reduced by the treatment, the $575 \mathrm{~nm}$ luminescence feature remained readily detectable. Other features in the initial spectrum, such as the line at $467 \mathrm{~nm}$, were removed during annealing. The features at $503 \mathrm{~nm}$ and $415 \mathrm{~nm}$ are the $\mathrm{H} 3$ and N3 centers respectively (see, e.g., Zaitsev, 2001, pp. 262-272 and 320-323), which are very commonly observed in natural nitrogen-containing diamond. In addition, the post-treatment spectrum contains a series of lines in the 451-459

Figure 18. The feature at approximately $1540 \mathrm{~cm}^{-1}$ that was present in the Raman spectrum of this brown $N$-doped CVD synthetic diamond sample before treatment (A) was completely absent (B) after $H P H T$ treatment removed the brown color. These spectra were recorded at room temperature with 785 nm excitation.

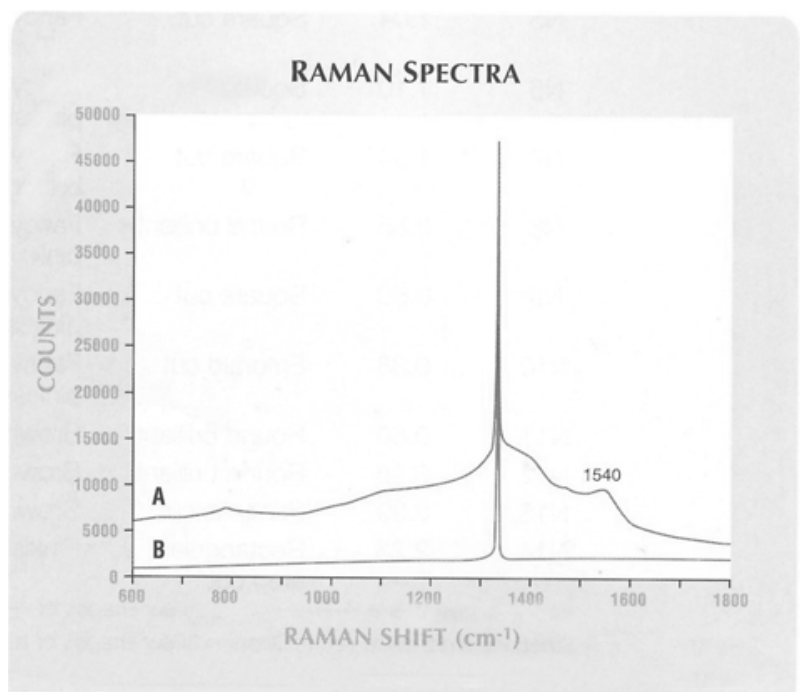


$\mathrm{nm}$ region that we have only observed for HPHTtreated CVD synthetic diamond. In all cases where the starting material showed the $737 \mathrm{~nm}$ luminescence feature with $633 \mathrm{~nm}$ excitation, this was still readily detectable after HPHT treatment, as noted by Wang et al. (2003). We never observed the pair of lines at 596 and $597 \mathrm{~nm}$ for HPHT-treated samples.

Whereas DiamondView images of as-grown samples showed orangy red luminescence, the images recorded after annealing were dominated by green luminescence (see, e.g., figure 19). Striations similar to those observed in DiamondView images of asgrown material were still visible after treatment.

Boron-Doped CVD Samples. All the CVD synthetic diamond samples grown from gas mixtures containing diborane showed colors equivalent to a range from Fancy Light grayish blue to Fancy Deep blue (again, see figure 5). All had optical absorption properties typical of type IIb diamond (see King et al., 1998). The color arose from boron-related absorption extending into the visible part of the spectrum, with decreasing absorption from the red to the blue. None of the samples we examined showed any of the impurity-related (i.e., $\mathrm{N}, \mathrm{H}$, or $\mathrm{Si}$ ) features we observed in the absorption or PL spectra of nitrogendoped CVD synthetic diamond.

As-grown samples exhibited octahedral $\{111\}$ growth faces and, for any given sample, the resulting $\{111\}$ growth sectors showed a more intense blue color than $\{100\}$ sectors formed above the cube $\{100\}$ surface of the substrate. SIMS analysis of approximately 40 samples indicated that the concentration of boron in the $\{100\}$ sector ranged from a few parts per billion to a few parts per million.

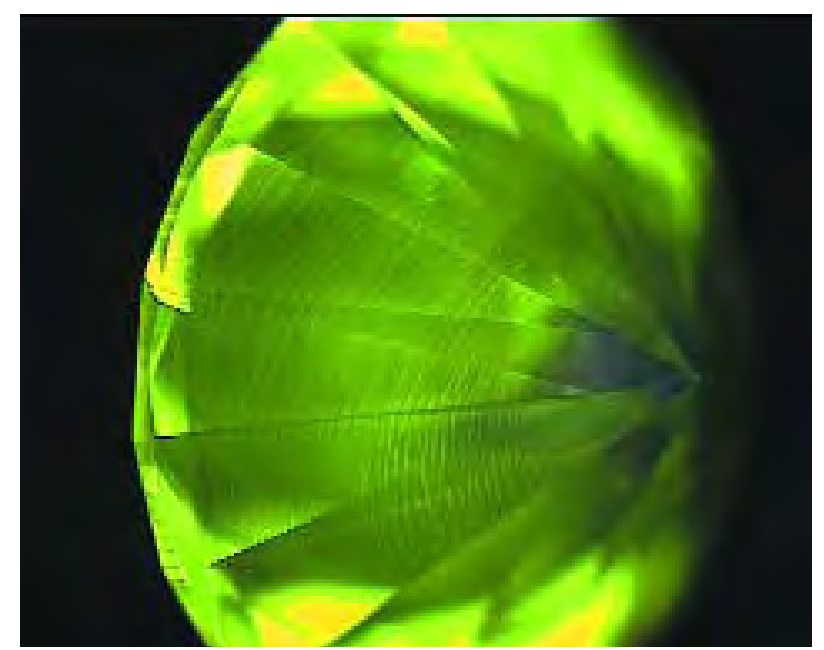

Figure 19. In this DiamondView image of a formerly brown 0.50 ct faceted CVD synthetic that has been made more colorless by HPHT annealing, the dominant component of the luminescence is now green but growth striations indicative of CVD synthetic diamond are still clearly seen. Photo by P. Martineau.

The weights, grades, and fluorescence properties (as obtained with a typical gemological UV lamp unit) of the five blue faceted stones we produced from CVD synthetic material are given in table 4 . When tested with the DiamondSure, all were referred.

When exposed to short-wave UV radiation in the DiamondView, all the boron-doped CVD synthetic diamond samples showed bright blue luminescence with some regions of light greenish blue luminescence. After such exposure, they showed blue phosphorescence that decayed over a period ranging from a few seconds to several tens of seconds.

DiamondView images of cross-sectional slices of as-grown boron-doped samples indicated that differ-

TABLE 4. Weights, grades and fluorescence reactions of five faceted boron-doped CVD synthetic diamond samples (produced for research and education only).

\begin{tabular}{|c|c|c|c|c|c|c|}
\hline \multirow{2}{*}{$\begin{array}{l}\text { Sample } \\
\text { number }\end{array}$} & \multirow{2}{*}{$\begin{array}{l}\text { Carat } \\
\text { weight }\end{array}$} & \multirow{2}{*}{ Cut } & \multirow{2}{*}{ Color } & \multirow{2}{*}{ Clarity } & \multicolumn{2}{|c|}{ UV fluorescence } \\
\hline & & & & & Long-wave & Short-wave \\
\hline B1 & 1.05 & Round brilliant & $\begin{array}{l}\text { Fancy Light } \\
\text { grayish blue }\end{array}$ & $\mathrm{VS}_{1}$ & Inert & $\begin{array}{l}\text { Greenish blue, and blue } \\
\text { phosphorescence }\end{array}$ \\
\hline B2 & 1.53 & Round brilliant & Fancy Light blue & IF & Inert & $\begin{array}{l}\text { Greenish blue, and blue } \\
\text { phosphorescence }\end{array}$ \\
\hline B3 & 1.85 & Cushion cut & $\begin{array}{l}\text { Fancy Intense } \\
\text { blue }\end{array}$ & $\mathrm{SI}_{1}$ & Inert & $\begin{array}{l}\text { Greenish blue, and blue } \\
\text { phosphorescence }\end{array}$ \\
\hline B4 & 1.03 & Square cut & Fancy Deep blue & $\mathrm{VS}_{2}$ & Inert & $\begin{array}{l}\text { Greenish blue, and blue } \\
\text { phosphorescence }\end{array}$ \\
\hline B5 & 2.64 & Square cut & Fancy Deep blue & $\mathrm{VS}_{1}$ & Inert & $\begin{array}{l}\text { Greenish blue, and blue } \\
\text { phosphorescence }\end{array}$ \\
\hline
\end{tabular}


ently oriented growth faces showed different luminescence properties. The luminescence from the octahedral $\{111\}$ and cube $\{100\}$ growth faces was generally greenish blue and blue, respectively. These different luminescence properties conform to the edges and corners of the substrate, where the differently oriented growth faces started to form, just as HPHT-grown synthetics show growth sectors radiating from the seed (Welbourn et al., 1996).

The final growth surface of all boron-doped samples showed growth steps, shallow pits, or a combination of both of these. DiamondView images of these surfaces revealed that the luminescence properties (color and intensity) of these steps and pits were different from those of adjacent regions where the surface was flat. After the original growth surface was removed during the preparation of free-standing CVD plates, we imaged the polished surface in the DiamondView. In every case, a pattern of features closely resembling that of the original growth surface was observed. DiamondView images clearly delineated the regions where growth had taken place on the differently oriented surfaces of steps and pits.

In the samples that were faceted, the intersection of the polished surface with growth sector boundaries showed up in DiamondView images. Jagged growth sector boundaries can be seen adjacent to the linear, step-related features in the upper two images of figure 20. The linear and bubble-like features also visible in figure 20 correspond to regions where growth has taken place on risers and in pits, respectively. We have never seen such features in DiamondView images of natural type $\mathrm{Ib}$ diamond; nor have they been reported in the literature. Similar features were observed in DiamondView images of all the boron-doped CVD synthetics we examined.

CVD Samples Grown in the Absence of Impurities other than Hydrogen. Samples grown under conditions created by exhaustive efforts to remove all impurities other than hydrogen from the growth environment were investigated using the DiamondView and cathodoluminescence topography. DiamondView and cathodoluminescence images of such samples showed only lines emitting blue luminescence. It is well known that dislocations in diamond tend to produce blue luminescence when excited by an electron beam or short-wave UV radiation. (For natural diamond, Kiflawi and Lang [1976] have demonstrated a one-to-one correspondence of CL-emitting lines and dislocations mapped using Xray topography.) We also studied these samples using absorption and photoluminescence spectroscopy. Apart from localized regions showing blue dislocation luminescence under short-wave ultraviolet excitation, we observed no spectroscopic features

Figure 20. The characteristic linear and bubble-like features seen in these DiamondView images of a $1.85 \mathrm{ct}$ faceted boron-doped CVD synthetic relate to the effect of growth surface steps (highlighted) and pits, respectively. Other features relate to growth sector boundaries.
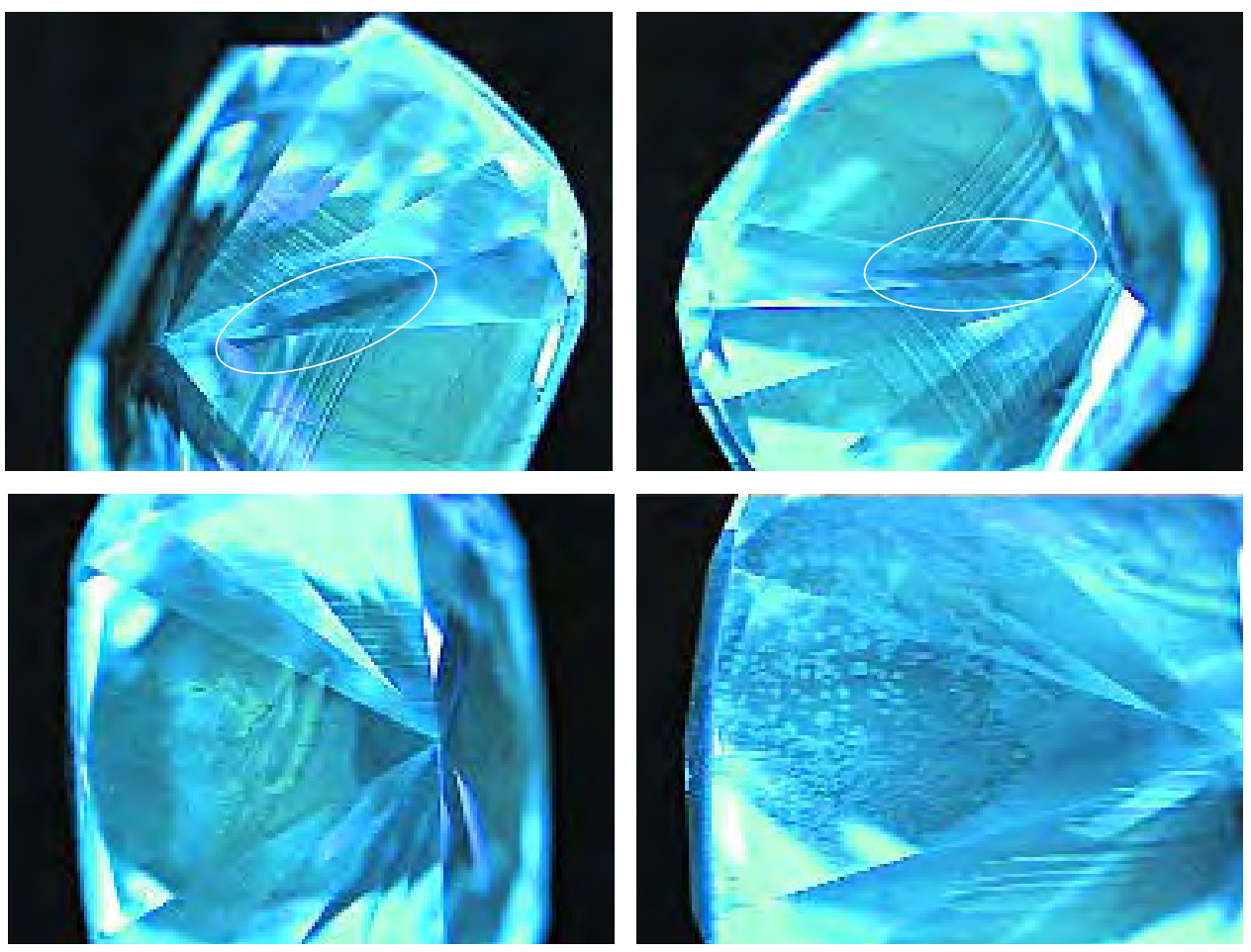
associated with either impurities or extended defects in the crystal structure.

When a polished high-purity CVD synthetic round brilliant was examined with the DiamondView, none of the orange luminescence characteristic of the $\mathrm{N}$-doped material was observed. Even when recorded with a long integration time on the instrument's high-gain setting and with the aperture fully open, as in figure 21, the image is dark except where blue dislocation luminescence is seen from regions of high dislocation density. We did not observe arrays of dislocations in mosaic patterns or in slip bands, as are typically seen in type IIa natural diamond (Lang, 1979), in any of the high-purity CVD synthetic diamond samples we investigated. Instead, the CL topographs and DiamondView images of high-purity CVD synthetic diamond showed blue dislocation luminescence as either individual or clustered streaks. Correlation of birefringence and luminescence images for free-standing plates showed that each region of anomalous birefringence was centered on a cluster of dislocations. Cross-sectional X-ray topographs showed contrast features similar to those seen in figure 9 .

Table 5 lists the grade equivalents and other relevant information for eight faceted stones produced from high-purity CVD synthetic diamond. When tested with the DiamondSure, all of these were referred. Examination with a DiamondView allowed them all to be identified as outlined above.

\section{DISCUSSION}

The Origin of Gemological Features. As a result of our experience with the CVD process and many different samples of CVD synthetic diamond, we have built up a general understanding of the origin of gemological features that may help in the identification of CVD synthetic diamond. Our experience is that, while such features cannot be relied on for definitive identification of CVD synthetics, if present they can be important clues. The most common features were described at the beginning of the Results section: birefringence, crystallographic orientation, different-colored layers, and inclusions.

In an HPHT synthesis process, growth proceeds outward from a small seed crystal that acts as a template for diamond formation (see, e.g., Welbourn et al., 1996). In the production of CVD synthetic diamond, the substrate serves the same purpose as a seed, but it generally has the form of a horizontally

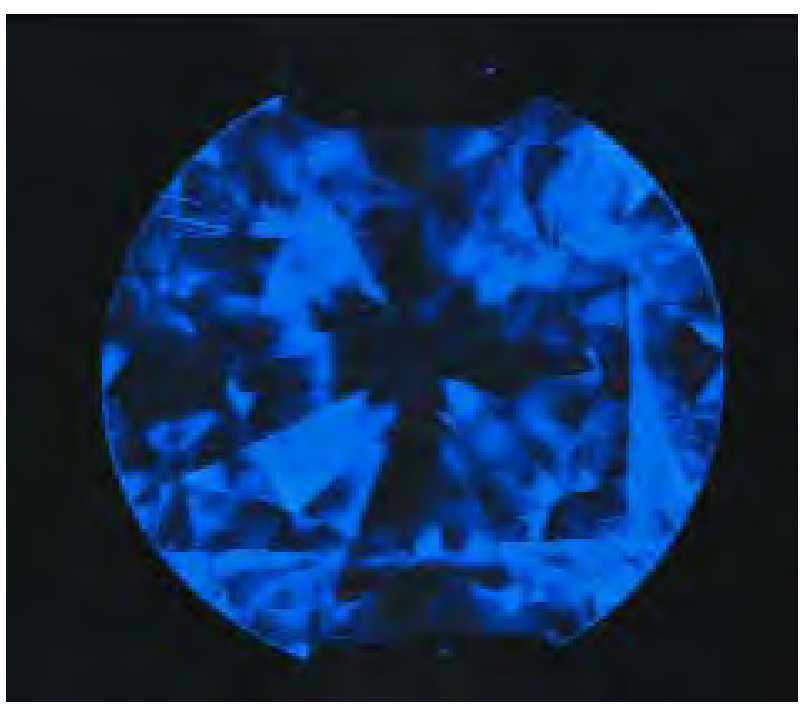

Figure 21. DiamondView images of this $0.30 \mathrm{ct} \mathrm{high-}$ purity CVD synthetic round brilliant did not show orange luminescence. The blue luminescence emanates from bundles of dislocations in arrangements not seen in natural diamond. High-purity CVD synthetics of this kind are not initially expected to be produced commercially. Photo by P. Martineau.

mounted diamond plate. The dominant faces of this plate have a chosen crystallographic orientation, often close to the cube orientation. Instead of growing out from a central seed crystal, CVD synthetic diamond will therefore initially form with one dominant growth face, with smaller growth faces forming at its edges, as illustrated in figure 22 .

In CVD synthetic diamond that is of high enough quality to be polished for jewelry purposes, like the material studied for this article, we have found that dislocations are the dominant kind of extended defect. Understanding the nature of these disloca-

TABLE 5. Weights and grades of eight faceted highpurity CVD synthetic diamond samples (produced for research and education only). ${ }^{\text {a }}$

\begin{tabular}{lclcc}
\hline $\begin{array}{l}\text { Sample } \\
\text { number }\end{array}$ & $\begin{array}{c}\text { Carat } \\
\text { weight }\end{array}$ & Cut & Color & Clarity \\
\hline HP1 & 0.31 & Round brilliant & $\mathrm{F}$ & $\mathrm{I}_{3}$ \\
HP2 & 0.30 & Round brilliant & $\mathrm{E}$ & $\mathrm{VS}_{1}$ \\
HP3 & 0.44 & Rose cut & $\mathrm{D}$ & $\mathrm{SI}_{1}$ \\
HP4 & 0.30 & Rose cut & $\mathrm{D}$ & $\mathrm{VVS}_{1}$ \\
HP5 & 0.21 & Rose cut & $\mathrm{D}$ & $\mathrm{SI}_{1}$ \\
HP6 & 0.50 & Round brilliant & $\mathrm{G}$ & $\mathrm{SI}_{1}$ \\
HP7 & 0.44 & Round brilliant & D/E & $\mathrm{VVS}_{2}$ \\
HP8 & 0.82 & Round brilliant & $\mathrm{E}$ & $\mathrm{VVS}_{1}$ \\
\hline
\end{tabular}

aAll were inert to long- and short-wave UV radiation. 
tions not only provides clues useful to the identification of CVD synthetic diamond, but it also aids interpretation of the birefringence shown by this material.

The results of cross-sectional X-ray topography suggest that dislocations tend to lie close to perpendicular to the growth surface and often originate at or near the interface between the CVD layer and its substrate. When a sample is viewed along the growth direction, dislocations will therefore tend to lie along the line of sight and, as a result, the effect of the strain field of the entire length of a particular dislocation is seen in one position in the field of view. This means that, when it is possible to view a sample along the growth direction using crossed

Figure 22. These diagrams show the morphological development of single-crystal CVD synthetic diamond for one particular set of growth conditions, starting from a substrate with six faces in cubic orientation. Four octahedral growth faces form in the corners, but the major cube $\{100\}$ growth faces are enlarged and cube $\{100\}$ edge growth faces can also be seen.

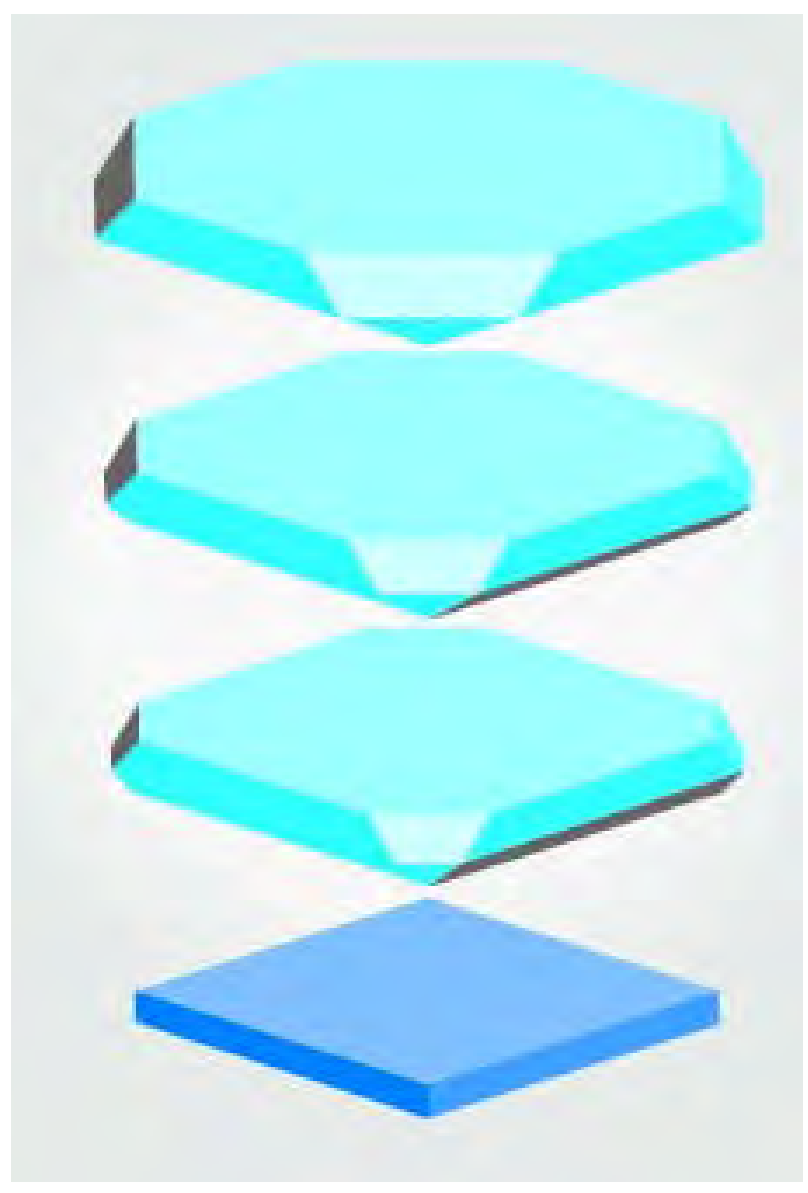

polarizers, localized birefringence may be observed in positions relating to sources of dislocations. Bundles of dislocations originating from individual point sources at or near the interface with the substrate give rise to characteristic birefringence patterns, such as those in figure 7. Wang et al. (2003, p. 278, figure 13) observed similar localized birefringence features in the CVD synthetic diamond samples they investigated. Such birefringence patterns are not generally seen in natural diamonds.

In our experience, the table-to-culet axis of a polished CVD synthetic stone will usually be almost parallel to the growth direction. Although it often will be impossible to observe birefringence with this viewing direction, it may be feasible for particularly flat cuts or when the culet is large. CVD synthetic diamond will generally have low birefringence compared to type IIa natural diamond, which is usually highly strained, as commented by Wang et al. (2003).

We have often observed lower-quality growth on octahedral growth faces, leading to four regions of defective material when a CVD layer is formed on a substrate that has a dominant face with cubic orientation. For a faceted stone, four-fold symmetry in the distribution of regions of lower quality may therefore raise suspicions that the item is a CVD synthetic.

We have found that it is relatively simple to change the composition of the gas mixture used during CVD growth. If this is done sequentially, a series of layers with different optical absorption or luminescence properties may be formed. In unstable processes, the growth conditions may temporarily change and this can lead to the formation of one or more growth event bands lying normal to the local growth direction. Wang et al. (2003, p. 277, figure 10) found evidence of such banding in at least one of the samples they investigated and explained it in terms of changes in growth conditions.

As CVD processes do not involve metal catalysts, CVD synthetic diamond does not generally contain metallic inclusions, but material grown using the hot filament technique may contain remnants of filament metals such as tungsten or tantalum. We have found that CVD synthetic diamond may contain inclusions of non-diamond carbon. When several inclusions have been incorporated at a given stage of the growth process, they will lie in a growth event band.

X-ray Topography of CVD Synthetic Diamond. Black et al. (1995) reported plan-view X-ray topography results for thin free-standing samples of CVD syn- 
thetic diamond. The layers investigated were of relatively low quality and only 70 to $80 \mu \mathrm{m}$ thick. Butler et al. (2002) presented a plan-view X-ray topograph of a thicker CVD sample grown by Apollo Diamond. It showed interesting cross-hatched contrast, but no cross-sectional topograph was presented.

$\mathrm{X}$-ray topography can be used to detect the interface between a CVD layer and its substrate (again, see figure 8 ). The V-shaped features above the interface suggest that dislocations nucleated at particular sites at or near the interface early in the growth process. In general, as a CVD layer grows, dislocations propagate in a direction almost perpendicular to the growth surface, leaving a record of the direction of growth. In our experience, X-ray topographs of natural diamond do not show the columnar texture that we have observed for CVD synthetic diamond (again, see figures 8 and 9). We therefore believe that $\mathrm{X}$-ray topography can give supporting evidence that may help identification of CVD synthetic diamond.

Impurities in the CVD Process. In CVD processes, impurities can be eliminated or added in a controlled way to produce doped CVD synthetic diamond material for a range of different technical applications. This also means that it is possible to produce various kinds of CVD synthetics for jewelry, which differ in impurity-related properties such as color and spectroscopic features. Because many potential identification features are impurity related, we investigated four growth processes involving different concentrations of impurities with the aim of developing a broad identification methodology for CVD synthetic diamond.

The results of our research indicate that, depending on the growth process and the impurities present in the growth environment, nitrogen, boron, hydrogen, and silicon may be present in detectable concentrations in CVD synthetic diamond (see, e.g., table 2). Hydrogen plays an important role in the CVD process (see, e.g., Goodwin and Butler, 1998), and because it is typically the most abundant gas in the growth environment, it is likely to be found in the resulting material. Nitrogen and boron content may result from deliberate or accidental sources in the growth process (see, e.g., Muller-Sebert et al., 1996; Locher et al., 1995), and silicon is often present as an unintentional impurity (see, e.g., Zaitsev, 2001, pp. 174-181). In attempts to produce diamond with novel electronic properties, some researchers have experimented with doping CVD synthetic diamond with other impurities, such as phosphorus and sulfur (see, e.g., Koizumi et al., 1998; NishitaniGamo et al., 2000). From a gemologist's point of view, nitrogen, boron, hydrogen, and silicon are likely to remain the most common impurities.

Samples Grown with Added Nitrogen. CVD synthetic diamond can be classified according to its impurity content in the same way as natural diamond and HPHT-grown synthetic diamond. It may be type $\mathrm{IIa}$, type $\mathrm{Ib}$, or type $\mathrm{IIb}$. When there is no boron present during growth, type IIa diamond will generally result, but in rare cases sufficient singly substitutional nitrogen may be incorporated for CVD synthetic diamond to be classified as type Ib.

Our experience has indicated that nitrogen is difficult to eliminate entirely from the growth environment. It may be present because of unintentional leaking of air into a CVD reactor or because it is an impurity in gases used in the CVD process. It is incorporated into CVD synthetic diamond in various kinds of defects that give characteristic spectroscopic signatures that can be useful as indicators of CVD synthetic diamond. It is known that even small concentrations of nitrogen in the starting gas can increase the growth rate (Muller-Sebert et al., 1996), and this may lead producers of CVD synthetic diamond to add nitrogen deliberately.

In terms of concentration, isolated nitrogen was one of the dominant nitrogen-related defects in the nitrogen-doped CVD synthetic diamond samples that we investigated. This corresponds to an isolated single nitrogen atom substituting for a carbon atom at a site in the diamond crystal with no other neighboring impurities or vacancies (missing carbon atoms). This defect causes a monotonic rise in absorption from about $500 \mathrm{~nm}$ into the blue and ultraviolet regions of the spectrum, with a broad absorption feature at $270 \mathrm{~nm}$ (see, for example, Zaitsev, 2001, pp. 343-344).

Wang et al. (2003) reported that many of the Apollo CVD synthetic diamond samples they investigated showed lines at 8753, 7354, 6856, 6425, 5564 , and $3123 \mathrm{~cm}^{-1}$, which is consistent with what Butler et al. (2002) also reported for an Apollo sample. These lines were identified as being hydrogenrelated by Fuchs et al. (1995a,b). They can be considered strong indicators of CVD synthetic diamond, because they have never been seen in any other kind of diamond. Note that we observed these lines only in the spectra of the as-grown CVD synthetic diamond samples doped with nitrogen. Like Wang et al. (2003), we found that they were 
removed by HPHT treatment.

The line we observed at $3323 \mathrm{~cm}^{-1}$ for some dark brown samples was also identified as being hydrogen-related by Fuchs et al. (1995a,b). Although it has been seen only in CVD synthetic diamond, it is not considered an important indicator because, even among nitrogen-doped samples, we observed it in relatively few cases and it, too, is removed by HPHT treatment.

Some CVD synthetic diamond contains hydrogen in paramagnetic defects that have been detected and characterized using electron paramagnetic resonance (EPR). Recent studies of nitrogen-doped single-crystal CVD synthetic diamond (Glover et al., 2003,2004 ) have identified two such defects that have never been observed in other kinds of diamond. Both of these were found to be present in the faceted CVD synthetic (M. E. Newton, pers. comm., 2004) investigated by Butler et al. (2002).

The nitrogen-vacancy $(\mathrm{N}-\mathrm{V})$ center is a very important defect in CVD synthetic diamond. It consists of an isolated single nitrogen atom, again at a site normally occupied by a carbon atom, but with one of its nearest-neighbor carbon atoms missing. It occurs in two different charge states: neutral and negatively charged. The latter gives rise to the photoluminescence system with a zero-phonon line at $637 \mathrm{~nm}$ (see, e.g., Zaitsev, 2001, pp. 197-203), and it is now generally believed that the neutral N-V center is responsible for the PL system with a zerophonon line at $575 \mathrm{~nm}$ (Lawson et al., 1998). Together they cause the orange or orangy red luminescence seen in DiamondView images of nitrogendoped CVD synthetic diamond. Nitrogen-vacancy centers are responsible for the orange luminescence that was observed when the $\mathrm{N}$-doped CVD synthetic diamond samples were exposed to UV radiation (254 $\mathrm{nm}$ or $365 \mathrm{~nm}$ ). Consequently, observation of predominantly orange luminescence should therefore trigger gemologists to study a stone in more detail.

The lines at $467 \mathrm{~nm}$ and $533 \mathrm{~nm}$ that we observed in the cathodoluminescence and PL spectra of nitrogen-doped CVD synthetic diamond have only been seen for CVD synthetic diamond (Zaitsev, 2001, pp. 245-246 and p. 300). We have shown, however, that HPHT treatment may remove them or substantially reduce their intensity.

All the Apollo synthetic diamond samples tested by Wang et al. (2003), and the one examined by Butler et al. (2002), showed a moderately strong PL line at $737 \mathrm{~nm}$. The $737 \mathrm{~nm}$ line has never been detected for natural diamond, and it has only been found in the spectra of HPHT-grown synthetic diamond in cases where silicon was deliberately added to the starting materials (Clark et al., 1995). Much of the CVD synthetic material that we have studied, however, does not show the $737 \mathrm{~nm}$ feature, and therefore it should not be relied on too heavily for identification. The center responsible is known to be very stable and is not likely to be altered by HPHT treatment (Clark et al., 1995).

The surface of CVD synthetic diamond has a tendency to show growth steps (van Enckevort et al., 1995), and our results indicate that differential uptake of impurity-related defects on the risers and terraces of these steps is responsible for the striations observed in luminescence images of polished samples. We have never observed such striations in luminescence (including DiamondView) images of non-CVD samples; nor have they been reported in the literature. The presence of such striations can, therefore, be considered a strong indicator of CVD synthetic diamond.

HPHT-Treated Nitrogen-Doped CVD Synthetic Diamond. It is now well known that the optical absorption properties of brown natural type Ila diamond can be changed by HPHT annealing (see, e.g., Fisher and Spits, 2000; Smith et al., 2000). Butler et al. (2003) reported that the brown color of CVD synthetic diamond can be reduced by HPHT annealing. Wang et al. (2003) reported results for HPHT annealing of three samples of CVD synthetic diamond but did not observe a color change in every case. We noted different responses to HPHT treatment depending on the starting material, but in every case we did observe a distinct reduction in ultraviolet and visible absorption (and a corresponding color change), with the absorption spectra of treated samples being dominated by absorption caused by isolated nitrogen atoms. In our experience, low-nitrogen (type $\mathrm{IIa} / \mathrm{Ib}$ ) natural diamond containing predominantly isolated nitrogen is extremely rare; the low concentrations of nitrogen atoms in type Ila natural diamond are generally in aggregated forms.

Brown color in type Ila natural diamond is associated with plastic deformation. We found no evidence that any of our brown CVD synthetic diamond samples were plastically deformed. Raman spectroscopy indicated that, unlike most brown natural type IIa diamond, brown CVD synthetic diamond contains significant amounts of non-diamond carbon that likely contributes to the absorption spectrum. After HPHT treatment removes the color, the non-diamond carbon is no longer present, almost certainly 


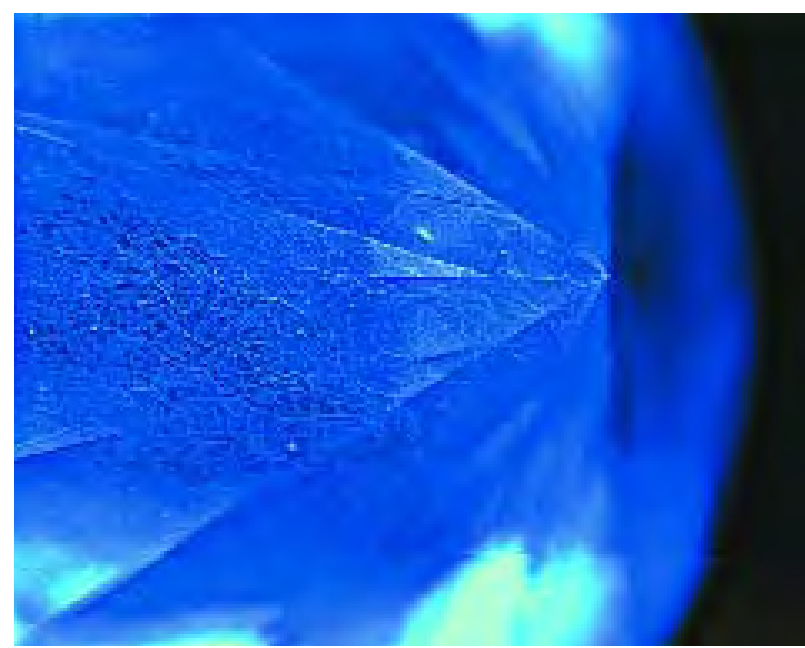

Figure 23. Blue luminescence and "mosaic" networks of polygonized dislocations are evident in this DiamondView image of a typical type II a natural diamond. Such networks were not seen in any of the CVD samples investigated in this study. (Imaged area: $3.6 \mathrm{~mm} \times 2.7 \mathrm{~mm}$.) Photo by $S$. Lawson.

because it has been converted to diamond. We cannot rule out the possibility that some of the UV-visible absorption of brown CVD synthetic diamond samples is caused by hydrogen-related defects that are removed by HPHT treatment.

It is clear from our results that HPHT annealing not only changes the absorption spectrum of brown CVD synthetic diamond, but it also affects the defects that contribute to PL spectra and images. Although some nitrogen-vacancy luminescence generally remains, DiamondView images of HPHTtreated nitrogen-doped CVD synthetic diamond samples tend to be dominated by green or greenblue luminescence with striations similar in form to those observed for the orange luminescence in asgrown samples.

Boron-Doped CVD Synthetic Diamond. DiamondView images of the B-doped CVD synthetic diamond samples we studied showed the effect of differential incorporation of boron on differently oriented surfaces that formed during growth. This gives rise to features we have never observed in DiamondView images of natural type $\mathrm{Ilb}$ diamond samples. We believe that these will remain reliable for the identification of boron-doped CVD synthetic diamond. Type IIb natural diamond samples we have investigated show a mosaic pattern of dislocations similar to that seen for natural type IIa diamond. Lang (1979) and Hanley et al. (1977) have described observation of such arrays of dislocations

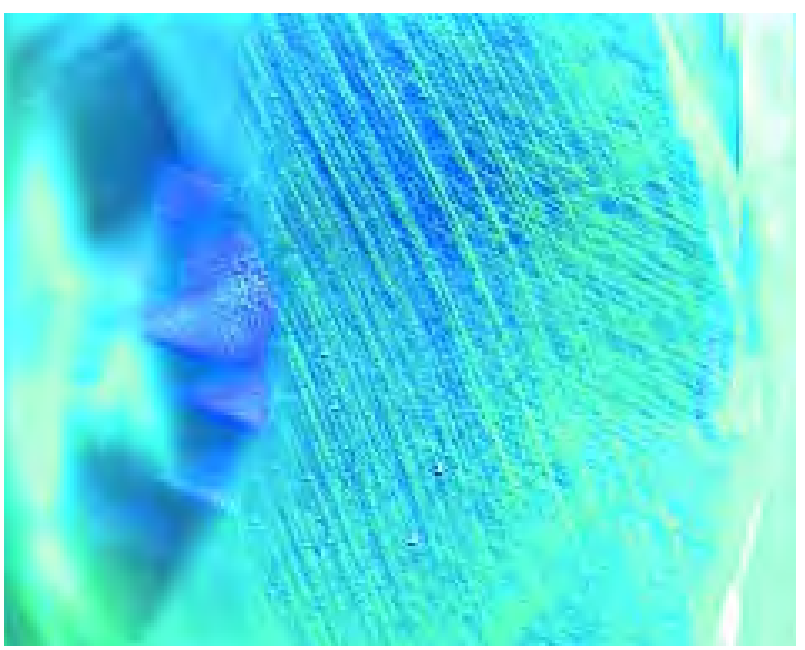

Figure 24. This DiamondView image of part of a plastically deformed natural type IIa diamond shows dislocations lying in slip bands, which were not seen in any of the CVD samples investigated in this study. (Imaged area: $3.6 \mathrm{~mm} \times 2.7 \mathrm{~mm}$.) Photo by P. Martineau.

in cathodoluminescence topographs of type Ilb natural diamond. We have never observed such arrays of dislocations in B-doped synthetic diamond, whether CVD or HPHT-grown.

High-Purity CVD Synthetic Diamond. DiamondView images of type IIa natural diamond typically show a high density of streaks of blue luminescence. The corresponding dislocations or bundles of dislocations show a variety of different patterns. In the majority of type Ila natural diamonds, we have found that they form a fairly random "mosaic" pattern (figure 23). In plastically deformed type IIa natural diamonds we have investigated, they tend to lie in slip bands on octahedral planes (figure 24). Some rare natural type Ila diamonds produce orange luminescence of the kind shown by CVD synthetic diamond. In these rare cases, however, DiamondView images show underlying dislocation structures that are characteristic of natural type IIa diamond (figure 25). We did not observe such arrays in any of the CVD synthetic diamond samples we studied, nor have they been reported in the literature to date. We therefore believe that, for type IIa diamond, the absence of such arrays of dislocations is a strong indicator of synthetic diamond.

It is possible to produce high-purity CVD synthetic diamond that shows no detectable impurity-related luminescence. This is technically very difficult, and growth rates are significantly lower than for nitrogen-doped CVD synthetic diamond. It is, therefore, 


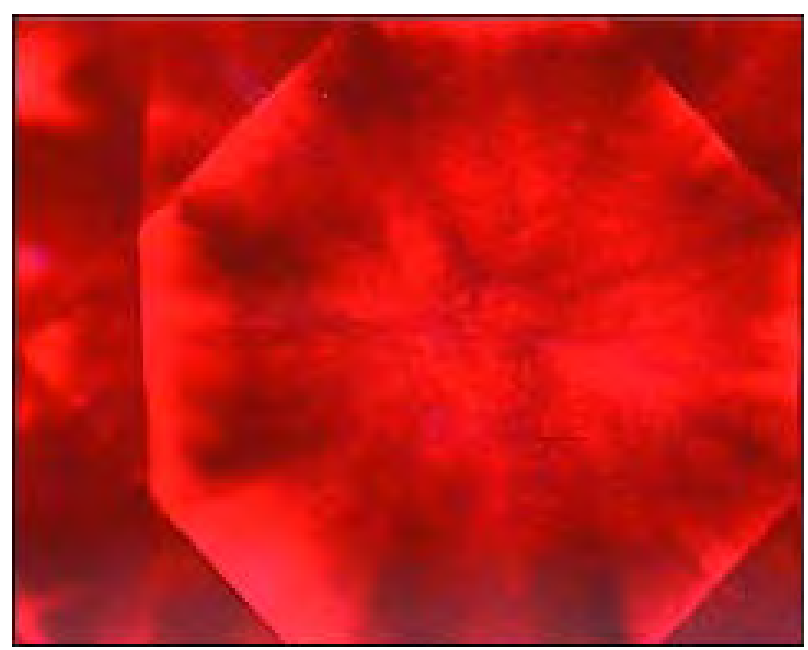

Figure 25. There are rare instances in which DiamondView images of a natural type II a diamond will show orange luminescence throughout. In such cases, we have observed underlying networks of dislocations of a kind that we have not seen for CVD synthetic diamond. (Imaged area: $3.6 \mathrm{~mm} \times 2.7 \mathrm{~mm}$.) Photo by S. Lawson.

unlikely that CVD synthetics of this kind will be commercially produced in the immediate future. The absence of detectable impurity-related luminescence would be very unusual for natural diamond; thus, in combination with the absence of dislocations in the mosaic or slip band arrays found in natural type Ila diamond, it would be a strong indicator of high-purity CVD synthetic diamond.

\section{IDENTIFICATION}

The key characterization results of this work are summarized in table 6. Nitrogen-doped CVD synthetic diamond shows a number of spectroscopic features not exhibited by either natural diamond or HPHT-grown synthetic diamond. When present, these are useful indicators of CVD synthetic material. However, our results show that it is possible to grow high-purity or boron-doped CVD synthetic diamond samples that show none of these features. In addition, many of the features of $\mathrm{N}$-doped material can be removed by HPHT treatment.

The Apollo Diamond samples provided to GIA for study contained low but significant concentrations of nitrogen. Their spectroscopic properties were almost identical to those we observed for samples grown with nitrogen added to the process gas. In particular, they showed $\mathrm{H}$-related absorption features, in the NIR $(8753,7354,6856,6425$ and 5564 $\mathrm{cm}^{-1}$ ) and at $3123 \mathrm{~cm}^{-1}$, which have never been reported for natural diamond. We concur with Wang et al. (2003) that these features represent a strong indicator of CVD synthetic diamond.

We also observed the 596/597 nm photoluminescence doublet reported by Wang et al. (2003), and this is another potentially useful indicator. One significant difference was that, whereas few of our samples showed the silicon-related $737 \mathrm{~nm}$ PL feature, Wang et al. (2003) observed this for every Apollo sample they investigated. This feature has never, to our knowledge, been reported for natural diamond and is therefore another useful indicator. It should, however, be emphasized that the absence of the $737 \mathrm{~nm}$ feature from the spectra of our more recently grown samples suggests that it may eventually be absent for material from other sources. Thus, the $737 \mathrm{~nm}$ feature, the $596 / 597 \mathrm{~nm}$ doublet, and the hydrogen-related absorption lines are useful only when present. Their absence is not a reliable indicator of natural or synthetic origin.

Following post-growth HPHT treatment, nitrogen-doped samples exhibited UV-visible absorption features that were caused predominantly by low concentrations of isolated nitrogen atoms. Lownitrogen natural diamond containing predominantly isolated nitrogen (type $\mathrm{IIa} / \mathrm{Ib}$ ) is extremely rare. Our treated CVD synthetic diamond samples also showed green or green/blue luminescence accompanied by PL features in the region of $451-459 \mathrm{~nm}$, with $325 \mathrm{~nm}$ excitation, that have not been observed in any other kind of diamond.

Although the DiamondSure was originally developed to screen for HPHT-grown synthetics, it refers all type IIa stones. We therefore feel confident that it will refer the CVD synthetic diamond currently being commercially produced, because Wang et al. (2003) have reported that it is type Ila. Some CVD synthetic diamond samples may contain high enough concentrations of isolated nitrogen to be classified as type Ib, but the DiamondSure also refers all type Ib stones.

CVD synthetic diamond material of the kind that Apollo Diamond currently is producing commercially shows orangy red luminescence (Butler et al., 2002; Wang et al., 2003) from nitrogen-related defects that generate spectral lines at $575 \mathrm{~nm}$ and $637 \mathrm{~nm}$. This luminescence is clearly visible in DiamondView images and, when seen, should alert the user. In very rare cases, natural type IIa diamond may show orange luminescence. Identification of CVD material therefore requires the observation of 
TABLE 6. The key characterization results for the four kinds of CVD synthetic diamond material studied.

\begin{tabular}{|c|c|c|c|c|}
\hline Property & Nitrogen-doped & $\begin{array}{l}\text { HPHT- annealed } \\
\text { nitrogen-doped }\end{array}$ & Boron-doped & High purity \\
\hline Color & $\begin{array}{l}\text { Faint brown } \\
\text { to brown }\end{array}$ & $\begin{array}{l}\text { Near-colorless or } \\
\text { green-brown }\end{array}$ & $\begin{array}{l}\text { Fancy Light blue to } \\
\text { Fancy Intense blue }\end{array}$ & Near-colorless or colorless \\
\hline UV-visible absorption & $\begin{array}{l}270 \mathrm{~nm} \\
360 \mathrm{~nm} \\
520 \mathrm{~nm} \\
624 \mathrm{~nm} \\
637 \mathrm{~nm} \\
737 \mathrm{~nm}\end{array}$ & $\begin{array}{l}270 \mathrm{~nm} \text { and associated } \\
\text { absorption }\end{array}$ & $\begin{array}{l}\text { Decreasing absorbance } \\
\text { from red to blue regions } \\
\text { of spectrum }\end{array}$ & Intrinsic absorption only \\
\hline IR absorption & $\begin{array}{l}8753,7354 \\
6856,6425 \\
5564,3323 \\
3123 \mathrm{~cm}^{-1}\end{array}$ & $3107 \mathrm{~cm}^{-1}$ & Boron-related & Intrinsic absorption only \\
\hline $\begin{array}{l}\text { Photoluminescence } \\
\text { spectroscopy }\end{array}$ & $\begin{array}{l}467 \mathrm{~nm} \\
533 \mathrm{~nm} \\
575 \mathrm{~nm} \\
596 \mathrm{~nm} \\
597 \mathrm{~nm} \\
637 \mathrm{~nm}\end{array}$ & $\begin{array}{l}415 \mathrm{~nm} \\
451-480 \mathrm{~nm} \text { region } \\
503 \mathrm{~nm} \\
575 \mathrm{~nm} \\
637 \mathrm{~nm}\end{array}$ & $\begin{array}{l}\text { Broad luminescence } \\
\text { band in the blue region } \\
\text { of the spectrum }\end{array}$ & $\begin{array}{l}\text { Only intrinsic and dislocation } \\
\text { luminescence }\end{array}$ \\
\hline DiamondView images & $\begin{array}{l}\text { Orange to orangy } \\
\text { red with striations } \\
\text { sometimes visible }\end{array}$ & $\begin{array}{l}\text { Green to blue-green with } \\
\text { striations sometimes } \\
\text { visible }\end{array}$ & $\begin{array}{l}\text { Blue with characteristic } \\
\text { features relating to } \\
\text { growth-surface morphology }\end{array}$ & $\begin{array}{l}\text { Dark except for blue } \\
\text { dislocation luminescence }\end{array}$ \\
\hline $\begin{array}{l}\text { Cathodoluminescence } \\
\text { spectroscopy }\end{array}$ & $\begin{array}{l}467 \mathrm{~nm} \\
533 \mathrm{~nm} \\
575 \mathrm{~nm}\end{array}$ & $\begin{array}{l}415 \mathrm{~nm} \\
503 \mathrm{~nm} \\
575 \mathrm{~nm}\end{array}$ & $\begin{array}{l}\text { Broad CL band in the } \\
\text { blue-green region of } \\
\text { the spectrum }\end{array}$ & $\begin{array}{l}\text { Only intrinsic and dislocation } \\
\text { luminescence }\end{array}$ \\
\hline $\begin{array}{l}\text { Cathodoluminescence } \\
\text { topography }\end{array}$ & $\begin{array}{l}\text { Orange with } \\
\text { striations }\end{array}$ & $\begin{array}{l}\text { Green or blue-green } \\
\text { with striations }\end{array}$ & $\begin{array}{l}\text { Blue-green with features } \\
\text { relating to surface } \\
\text { morphology }\end{array}$ & $\begin{array}{l}\text { Only intrinsic and dislocation } \\
\text { luminescence }\end{array}$ \\
\hline $\begin{array}{l}\text { X-ray topography } \\
\text { (cross-sectional) }\end{array}$ & $\begin{array}{l}\text { Streaks nearly } \\
\text { parallel to growth } \\
\text { direction }\end{array}$ & $\begin{array}{l}\text { Streaks nearly } \\
\text { parallel to growth } \\
\text { direction }\end{array}$ & $\begin{array}{l}\text { Streaks nearly } \\
\text { parallel to growth } \\
\text { direction }\end{array}$ & $\begin{array}{l}\text { Streaks nearly } \\
\text { parallel to growth } \\
\text { direction }\end{array}$ \\
\hline
\end{tabular}

a These represent the results for the majority of samples tested.

additional features indicative of CVD synthetic diamond, such as the striations described earlier, or the absence of the dislocation networks found in type IIa natural diamond.

Although DiamondPLus was primarily designed for rapid screening for HPHT-treated type II diamonds, it will detect a range of spectroscopic features associated with CVD synthetic diamond of the kind currently being commercially produced. Wang et al. (2003) reported that all the Apollo Diamond samples they investigated showed 575, 637 , and $737 \mathrm{~nm}$ photoluminescence features. Based on this information, we are confident that DiamondPLus would give a "refer CVD" result for these samples. In our experience, the $737 \mathrm{~nm}$ feature is not removed by HPHT annealing.

In cases where doubt remains after a stone has been studied in a DiamondView and DiamondPLus, $\mathrm{X}$-ray topography also can provide a useful indication of the mode of growth. The directional contrast streaks of the kind that we have observed in crosssectional topographs are a strong indicator of CVD synthetic diamond.

\section{CONCLUSIONS}

Our research has shown that it is possible to produce a variety of CVD synthetic diamond materials with differing properties. We have described the properties of nitrogen-doped, annealed nitrogen-doped, boron-doped, and high-purity CVD synthetic diamond. Comparison of our results with those of Butler at al. (2002) and Wang et al. (2003) indicates that the Apollo Diamond samples they studied fit into the category we have called nitrogen-doped. Such material shows a range of spectroscopic features that can be used to identify it, as we summarized in the last section.

Although there are useful gemological clues (such as observation of characteristic birefringence or orange fluorescence) and some CVD material shows spectroscopic features that are not observed for other kinds of diamond (such as the $737 \mathrm{~nm}$ photoluminescence feature or the H-related absorption lines), our research has shown that these gemological and spectroscopic indicators cannot be relied on in all cases.

Our results indicate that surface luminescence 
images of the kind that can be generated using the DiamondView provide very useful information for identifying all the kinds of CVD synthetics that we have produced in our research, including those that show no gemological or spectroscopic indicators. Luminescence imaging is already used by the major gemological laboratories to study unusual stones, and the results of our research suggest that it will play a central role in the identification of CVD synthetics in the future.

Apollo Diamond has a stated policy of disclosure and marking (Priddy, 2003). The combination of disclosure and reliable detection methods will help protect consumer confidence that CVD synthetics will not be misrepresented as natural diamond and will facilitate informed jewelry buying.

\section{ABOUT THE AUTHORS}

The authors work in the Physics Department of the DTC Research Centre, Berkshire, United Kingdom. Dr. Martineau is a principal scientist, working mainly on CVD synthetic diamond, and Dr. Lawson is project manager for Consumer Confidence Technical Research. Mr. Taylor and Ms. Quinn are senior techni cians, Mr. Evans is a senior research assistant, and Mr.Crowder is a principal technician.

ACKNOWLEDGMENTS: The authors thank all the members of the DTC Research Centre, Maidenhead, who have been involved in the CVD research program. Particular recognition is due to C. J. Kelly and J. A. Jones for carrying out sample processing work, and to M. Cooper, C. M. Welbourn, and D. Fisher for helpful discussions and general guidance over many years. The authors are also grateful to the members of the CVD synthesis team at Element Six for the high level of expertise, commitment, and enthusiasm they have shown through out this work. Particular recognition is due to G. A. Scarsbrook and D. J. Twitchen.

\section{REFERENCES}

Angus J.C. (2002) A short history of diamond synthesis. In J. Asmussen and D.K. Reinhard, Eds., Diamond Films Handbook, Marcel Dekker, New York, pp. 17-26.

Bachmann P.K. (1998) Microwave plasma chemical vapor deposition of diamond. In M.A. Prelas, G. Popovici, and L.K. Bigelow, Eds., Handbook of Industrial Diamonds and Diamond Films, Marcel Dekker, New York, pp. 821-850.

Badzian A., Badzian T. (1993) Diamond homoepitaxy by chemical vapor deposition. Diamond and Related Materials, Vol. 2, No. 2-4, pp. 147-157.

Black D., Burdette H., Linares R., Doering P., Marchywka M., Pehrsson P. (1995) X-ray diffraction imaging of free-standing single-crystal CVD diamond films. In K.V. Ravi, J.P. Dismukes, J.L. Davidson, K.E. Spear, R.H. Hauge, and B.V. Spitsyn, Eds., Fourth International Symposium on Diamond Materials, Electrochemical Society, Reno, Nevada, Vol. 95-4, pp. 467-472.

Bundy F.P., Hall H.T., Strong H.M., Wentorf R.J. (1955) Man-made diamond. Nature, Vol. 176, pp. 51-54.

Butler J.E., Kennedy T.A., Colton J.S., Quadri S., Linares R., Doering P., Newton M., Glover C., Smith H., Collins A. (2002) Analysis of large single-crystal CVD diamond. 8th International Conference New Diamond Science and Technology, July 21-26, Melbourne, www.conferences.unimelb.edu.au/ icndst-8/Presentations/p1-01-1.pdf [date accessed: 04/13/04].

Butler J.E., Charles S., Feygelson B., Yan C.-H., Mao H.-K., Hemley R. (2003) Characterization of HPHT annealed single-crystal CVD diamond. Proceedings of the De Beers Diamond Conference, July 7-9, Cambridge, U.K., pp. 24.1-24.5.

Clark C.D., Collins A.T., Woods G.S. (1992) Absorption and luminescence spectroscopy. In J.E. Field, Ed., The Properties of Natural and Synthetic Diamond, Academic Press, London, pp. 35-79.

Clark C.D., Kanda H., Kiflawi I., Sittas G. (1995) Silicon defects in diamond. Physical Review B, Vol. 51, No. 23, pp. 16681-16688.

Coe S.E., Sussmann R.S. (2000) Optical, thermal and mechanical properties of CVD diamond. Diamond and Related Materials, Vol. 9, No. 9-10, pp. 1726-1729.

Davies G. (1984) Diamond, Adam Hilger Ltd., Bristol.

Eversole W.G. (1962a) Synthesis of Diamond. U.S. patent 3,030,187, issued April 17.

Eversole W.G. (1962b) Synthesis of Diamond. U.S. patent 3,030,188, issued April 17

Fisher D., Spits R.A. (2000) Spectroscopic evidence of GE POL HPHT-treated natural type IIa diamonds. Gems e) Gemology, Vol. 36, No. 1, pp. 42-49.

Fritsch E., Conner L., Koivula J.I. (1989) A preliminary gemological study of synthetic diamond thin films. Gems ↔ Gemology, Vol. 25, No. 2, pp. 84-90.

Fuchs F., Wild C., Schwarz K., Muller-Sebert W., Koidl P. (1995a) Hydrogen induced vibrational and electronic transitions in chemical vapor deposited diamond, identified by isotopic substitution. Applied Physics Letters, Vol. 66, No. 2, pp. 177-179.

Fuchs F., Wild C., Schwarz K., Koidl P. (1995b) Hydrogen-related IR absorption in chemical vapour deposited diamond. Diamond and Related Materials, Vol. 4, No. 5-6, pp. 652-656.

Glover C., Newton M.E., Martineau P.M., Twitchen D.J., Baker J.M. (2003) Hydrogen incorporation in diamond: The nitrogenvacancy-hydrogen complex. Physical Review Letters, Vol. 90, No. 18, pp.185507-1-1855057-4.

Glover C., Newton M.E., Martineau P.M., Twitchen D.J. (2004) Hydrogen incorporation in diamond: The vacancy-hydrogen complex. Physical Review Letters, Vol. 92, No. 13, pp. 135502$1-135502-4$.

Goodwin D.G., Butler J.E. (1998) Theory of diamond chemical vapor deposition. In M.A. Prelas, G. Popovici and L.K. Bigelow, Eds., Handbook of Industrial Diamonds and Diamond Films, Marcel Dekker, New York, pp. 527-581.

Grotjohn T.A., Asmussen J. (2002) Microwave plasma-assisted diamond film deposition. In J. Asmussen and D.K. Reinhard, Eds. Diamond Films Handbook, Marcel Dekker, New York, pp. 211-302.

Hanley P.L., Kiflawi I., Lang A.R. (1977) On topographically identifiable sources of cathodoluminescence in natural diamonds. Philosophical Transactions of the Royal Society of London A, Vol. 284, pp. 329-368.

Heberlein J.V.R., Ohtake N. (2002) Plasma torch diamond deposition. In J. Asmussen and D.K. Reinhard, Eds., Diamond Films Handbook, Marcel Dekker, New York, pp. 141-210. 
Isberg J., Hammersberg J., Johansson E., Wikstrom T., Twitchen D.J., Whitehead A.J., Coe S.E., Scarsbrook G.A. (2002) High carrier mobility in single-crystal plasma-deposited diamond. Science, Vol. 297, No. 5587, pp. 1670-1672.

Janssen G., van Enckevort W.J.P., Schaminee J.J.D., Vollenberg W., Giling L.J., Seal M. (1990) Rapid single crystalline diamond growth by acetylene-oxygen flame deposition. Journal of Crystal Growth, Vol. 104, No. 3, pp. 752-757.

Janssen G., Vollenberg W., Gilling L.J., van Enckevort W.J.P., Schaminee J.J.D., Seal M. (1991) Rapid growth of single-crystal diamond on diamond substrates. Surface and Coatings Technology, Vol. 47, No. 1-3, pp. 113-126.

Johnson M.L., Koivula J.I., Eds. (1997) Gem News: Synthetic diamond thin film jewelry. Gems et Gemology, Vol. 33, No. 2, pp. $143-144$.

Kiffer A.D. (1956) Synthesis of diamond from carbon monoxide. Report, Tonowanda Laboratories, Linde Air Products Co., June 6.

Kiflawi I., Lang A.R. (1976) On the correspondence between cathodoluminescence images and X-ray diffraction contrast images of individual dislocations in diamond. Philosophical Magazine, Vol. 33, No. 4, pp. 697-701.

King J.M., Moses T.M., Shigley J.E., Welbourn C.M., Lawson S.C., Cooper M.C. (1998) Characterizing natural-color type IIb blue diamonds. Gems et Gemology, Vol. 34, No. 4, pp. 246-268.

Koizumi S., Kamo M., Sato Y., Mita S., Sawabe A., Reznik A., Uzan-Saguy C., Kalish R. (1998) Growth and characterization of phosphorus doped n-type diamond thin films. Diamond and Related Materials, Vol. 7, pp. 540-544.

Landstrass M.I., Plano M.A., Moreno M.M., McWilliams S., Pan L.S., Kania D.R., Han S. (1993) Device properties of homoepitaxially grown diamond. Diamond and Related Materials, Vol. 2, No. 5-7, pp. 1033-1037.

Lang A.R. (1979) Internal structure. In J.E. Field, Ed., The Properties of Diamond, Academic Press, London, pp. 425-469.

Lang A.R., Moore M., Walmsley J.C. (1992) Diffraction and imaging studies of diamond. In J.E. Field, Ed., The Properties of Natural and Synthetic Diamond, Academic Press, London, pp. 215-258.

Lawson S.C., Fisher D., Hunt D.C., Newton M.E. (1998) On the existence of positively-charged single substitutional nitrogen in diamond. Journal of Physics C: Condensed Matter, Vol. 10, No. 27, pp. 6171-6180.

Linares R., Doering P. (1999) Properties of large single crystal diamond. Diamond and Related Materials, Vol. 8, No. 2-5, pp. 909-915.

Locher R., Wagner I., Fuchs F., Maier M., Gonon P., Koidl P. (1995) Optical and electrical characterization of boron-doped diamond films. Diamond and Related Materials, Vol. 4, No. 5-6, pp. 678-683.

Matsumoto S., Sato Y., Kamo M., Setaka N. (1982a) Vapor deposition of diamond particles from methane. Japanese Journal of Applied Physics, Vol. 21, No. 4, pp. L183-L185.

Matsumoto S., Sato Y., Tsutsumi M., Setaka N. (1982b) Growth of diamond particles from methane-hydrogen gas. Journal of Materials Science, Vol. 17, pp. 3106-3112.

Muller-Sebert W., Worner E., Fuchs F., Wild C., Koidl P. (1996) Nitrogen induced increase of growth rate in chemical vapor deposition of diamond. Applied Physics Letters, Vol. 68, No. 6, pp. $759-760$.

Nishitani-Gamo M., Yasu E., Xiao C., Kikuchi Y., Ushizawa K., Sakaguchi I., Suzuki T., Ando T. (2000) Sulfur-doped homoepitaxial (001) diamond with n-type semiconductive properties. Diamond and Related Materials, Vol. 9, No. 3-6, pp. 941-947.

Plano M.A., Moyer M.D., Moreno M.M., Black D., Burdette H., Robins L., Pan L.S., Kania D.R., Banholzer W. (1994) Characterization of a thick homoepitaxial CVD diamond film. In C.H. Carter, G. Gildenblat, S. Nakamura, R.J. Nemanich, Eds., Diamond, SiC and Nitride Wide Bandgap Semiconductors, Materials Research Society, Warrendale, PA, pp. 307-312.
Priddy S. (2003) Apollo Diamond to release CVD diamonds in Q4. Rapaport News, www.diamonds.net/news/newsitem.asp?num= 8374 [date accessed: 04/13/04].

Schermer J.J., van Enckevort W.J.P., Giling L.J. (1994) Flame deposition and characterization of large type IIa diamond single crystals. Diamond and Related Materials, Vol. 3, No. 4-6, pp. 408-416.

Schermer J.J., de Theije F.K., Giling L.J. (1996) Mosaic growth of diamond: A study of homoepitaxial flame deposition and etching of $\{001\}$-oriented diamond layers. Journal of Crystal Growth, Vol. 165, No. 4, pp. 387-401.

Shigley J.E., Fritsch E., Stockton C.M., Koivula J.I., Fryer C.W. Kane R.E. (1986) The gemological properties of the Sumitomo gem-quality synthetic yellow diamonds. Gems et Gemology, Vol. 22, No. 4, pp. 192-208.

Shigley J.E., Fritsch E., Stockton C.M., Koivula J.I., Fryer C.W. Kane R.E., Hargett D.R., Welch C.W. (1987) The gemological properties of the De Beers gem-quality synthetic diamonds. Gems « Gemology, Vol. 23, No. 4, pp. 187-206.

Smith C.P., Bosshart G., Ponahlo J., Hammer V.M.F., Klapper H., Schmetzer K. (2000) GE POL diamonds: Before and after. Gems (4) Gemology, Vol. 36, No. 3, pp. 192-215.

Sussmann R.S., Brandon J.R., Scarsbrook G.A., Sweeney C.G. Valentine T.J., Whitehead A.J., Wort C.J.H. (1994) Properties of bulk polycrystalline CVD diamond. Diamond and Related Materials, Vol. 3, No. 4-6, pp. 303-312.

Tsuno T., Imai T., Fujimori N. (1994) Twinning structure and growth hillock on diamond (001) epitaxial film. Japanese Journal of Applied Physics, Vol. 33, pp. 4039-4043.

Valentine T.J., Whitehead A.J., Sussmann R.S., Wort C.J.H., Scarsbrook G.A. (1994) Mechanical property measurements of bulk polycrystalline CVD diamond. Diamond and Related Materials, Vol. 3, No. 9, pp. 1168-1172.

van Enckevort W.J.P., Janssen G., Schermer J.J., Giling L.J. (1995) Step-related growth phenomena on exact and misoriented $\{001\}$ surfaces of CVD-grown single-crystal diamonds. Diamond and Related Materials, Vol. 4, No. 4, pp. 250-255.

Wang W., Moses T., Linares R., Shigley J.E., Hall M., Butler J.E. (2003) Gem-quality synthetic diamonds grown by a chemical vapor deposition (CVD) method. Gems \&) Gemology, Vol. 39, No. 4 , pp. $268-283$

Welbourn C.M., Cooper M., Spear P.M. (1996) The De Beers natural versus synthetic diamond verification instruments. Gems et) Gemology, Vol. 32, No. 3, pp. 156-169.

Welbourn C.M., Williams R. (2002) DTC comes to diamonds defense. Rapaport Diamond Report, Vol. 25, No. 17, pp. 46-47.

Wild C., Koidl P., Muller-Sebert W., Walcher H., Kohl R., Herres N., Locher R., Samlenski R., Brenn R. (1993) Chemical vapour deposition and characterization of smooth $\{100\}$-faceted diamond films. Diamond and Related Materials, Vol. 2, No. 2-4, pp. $158-168$.

Wolden C.A. (2002) Combustion synthesis of diamond. In J. Asmussen and D.K. Reinhard, Eds., Diamond Films Handbook, Marcel Dekker Inc., New York, pp. 303-323.

Woods G.S., Collins A.T. (1983) Infrared absorption spectra of hydrogen complexes in type I diamonds. Journal of Chemistry and Physics of Solids, Vol. 44, No. 5, pp. 471-475.

Wort C.J.H., Sweeney C.G., Cooper M.A., Scarsbrook G.A. Sussmann R.S. (1994) Thermal properties of bulk polycrystalline CVD diamond. Diamond and Related Materials, Vol. 3, No. 9, pp. 1158-1167.

Yan C.-S., Vohra Y.K., Mao H.-K., Hemley R.J. (2002) Very high growth rate chemical vapor deposition of single-crystal diamond. Proceedings of the National Academy of Sciences of the United States of America, Vol. 99, No. 20, pp. 12523-12525.

Yehoda J.E. (2002) Thermally assisted (hot-filament) deposition of diamond. In J. Asmussen and D.K. Reinhard, Eds., Diamond Films Handbook, Marcel Dekker, New York, pp. 119-140.

Zaitsev A.M. (2001) Optical Properties of Diamond. SpringerVerlag, Berlin, 502 pp. 